\title{
Discriminating irrigated and rainfed olive orchards with thermal ASTER imagery and DART 3D simulation
}

\author{
G. Sepulcre-Cantó ${ }^{\text {a }}$, P.J. Zarco-Tejada a,*, J.A. Sobrino ${ }^{\text {b }}$, J.A.J. Berni ${ }^{\text {a }}$, \\ J.C. Jiménez-Muñoz ${ }^{\text {b }}$, J.P. Gastellu-Etchegorry ${ }^{c}$ \\ ${ }^{a}$ Instituto de Agricultura Sostenible (IAS), Consejo Superior de Investigaciones Científicas (CSIC), Alameda del Obispo, s/n, 14004 - Córdoba, Spain \\ ${ }^{\mathrm{b}}$ Global Change Unit, Department of Thermodynamics, Faculty of Physics, University of Valencia, Valencia, Spain \\ ${ }^{\mathrm{c}}$ CESBIO, 18, Avenue Edouard Belin, 31401 Toulouse Cedex 9, France
}

\section{A R T I C L E I N F O \\ Article history: \\ Received 9 June 2008 \\ Received in revised form 2 December 2008 \\ Accepted 4 December 2008}

\section{Keywords:}

ASTER

Canopy temperature

Vegetation index

Rainfed

Irrigated

DART

Radiative transfer

\begin{abstract}
A B S T R A C T
This work provides a description of the research conducted to assess methods for the discrimination between irrigated and rainfed open-tree canopies using advanced spaceborne thermal emission and reflection radiometer (ASTER) satellite imagery and discrete anisotropic radiative transfer (DART) radiative transfer 3D simulation model. Summer and winter ASTER images were acquired over a study area in southern Spain during a 6-year period. A total of 1076 olive orchards were monitored in this area, gathering the field location, field area, tree density, and whether the field was drip irrigated or rainfed. Surface temperature images from ASTER were estimated using the temperature and emissivity separation (TES) method. A panchromatic ortho-rectified imagery dataset collected over the entire area at $0.5 \mathrm{~m}$ resolution was used to estimate orchard vegetation cover for each field. Results for summer ASTER thermal images showed differences between irrigated and rainfed orchards of up to $2 \mathrm{~K}$ for fields with the same percentage cover, decreasing the differences in ASTER winter images. An approach based on a cumulative index using temperature and the normalized difference vegetation index (NDVI) information for the 6-year ASTER time-series was capable of detecting differences between irrigated and rainfed open-canopy orchards, obtaining $80 \%$ success on field-to-field assessments. The method considered that irrigated orchards with equal vegetation cover would yield lower temperature and NDVI than rainfed orchards; an overall accuracy of $75 \%$ and a kappa ( $\kappa$ ) of 0.34 was obtained with a supervised classification method using visible, near infrared and temperature information for the 6-year ASTER imagery series. These experimental ASTER results were confirmed with DART radiative transfer 3D model used to simulate the influence of vegetation cover, leaf area index (LAI) and background temperature on the irrigated and rainfed orchard temperature at the ASTER pixel size.
\end{abstract}

(c) 2008 Elsevier B.V. All rights reserved.

\section{Introduction}

Understanding crop water relations is critical for the application of optimum management practices to obtain maximum productivity levels. In particular, the accurate and timely detection of crop water stress is a key factor for water management purposes and water supply requirements (Fereres and Soriano, 2007). In addition to water stress detection, which is linked to the leaf water potential, the estimation of vegetation water content from remote sensing imagery has important implications in forestry (Gao and Goetz, 1995), it is essential for drought assessment (Peñuelas et al., 1993),

\footnotetext{
* Corresponding author. Tel.: +34 957499 280/676 954 937;

fax: +34957 499252.

E-mail address: pzarco@ias.csic.es (P.J. Zarco-Tejada).

URL: http://quantalab.ias.csic.es
}

and it is a major driver in predicting fire risk (Chandler et al., 1983; Pyne et al., 1996; Ustin et al., 1998).

The use of temperature to detect crop water stress (Idso et al., 1981 ; Jackson et al., 1981, 1977) has been widely studied, mainly using infrared thermal sensors on herbaceous crops. Later, some studies focused in the combination of surface temperature and vegetation indices to account for canopy structural effects, proposing the water deficit index (WDI) (Moran et al., 1994) for water stress detection, or the temperature-vegetation dryness index (TVDI) (Sandholt et al., 2002) to provide information of vegetation and soil moisture conditions at regional scale. Recently, work by SepulcreCantó et al. $(2006,2007)$ proved the capability of high resolution ( $2 \mathrm{~m}$ ) airborne thermal remote sensing imagery to detect water stress in orchard canopies, assessing the potential application of water stress detection methods to thermal advanced spaceborne thermal emission and reflection radiometer (ASTER) imagery. The study demonstrated the feasibility for mapping airborne-estimated crown temperature minus air temperature $\left(T_{\mathrm{c}}-T_{\mathrm{a}}\right)$ as an indicator of 
crown stem water potential and conductance in open-canopy crops (olive and peach trees) grown under regulated deficit irrigation. In particular, high-resolution thermal imagery was capable of identifying individual trees under different transpiration levels, yielding up to $5 \mathrm{~K}$ difference as detected by the airborne hyperspectral scanner (AHS) thermal sensor.

These results were particularly important because the remote detection of water stress in open canopies poses additional complexity due to pixel-level effects from direct soil and shadow components. In addition, orchard crops are planted in varying grid patterns, therefore resulting in different vegetation coverage levels that affect both vegetation indices (i.e. NDVI) and effective temperature $(T)$ as a function of each scene component. In a simulation study, Sepulcre-Cantó et al. (2007) assessed the applicability of the method to medium-resolution sensors, demonstrating the potential detection of water stress levels in open canopies with ASTER thermal imagery. The issue of mixed pixels from background and shadow components have also important implications in empirical and single-source energy balance ET estimation models. SEBAL (Bastiaanssen et al., 1998) or METRIC (Allen et al., 2005) models use NDVI and $T$ as inputs, potentially leading to erroneous ET estimates due to large $T-T_{\mathrm{a}}$ values (in the order of $15-20 \mathrm{~K}$ ) which in fact represent only $2-3 \mathrm{~K}$ $T_{\mathrm{c}}-T_{\mathrm{a}}$ (crown temperature minus air temperature) differences. These previous studies conducted with high and medium resolution thermal imagery (airborne and satellite scales) suggest that pure-crown temperature can be used to monitor crown transpiration levels and, as a result, potentially useful for discriminating irrigation management practices. Nevertheless, previous attempts to discriminate between irrigated and rainfed fields for land classification purposes were based on leaf area index (LAI) (NDVI) trends (Mo et al., 2005; Ines and Honda, 2005), obtaining information at sub-pixel level from medium and low spatial resolution imagery. Other studies have used the relationship between $T_{\mathrm{c}}$ and NDVI (reviewed by Kustas and Norman (1996)) proving the capability of combining the thermal and the vegetation index NDVI for evapotranspiration estimation. Nevertheless, these methods that successfully discriminated irrigated from rainfed herbaceous crops may not be suitable for some perennial canopies, both natural vegetation and agricultural crops, where changes in structure as function of water availability are very slow, not visually detectable, and the pixel is generally mixed with scene components.

Therefore, further studies are needed to account for scene components when monitoring non-homogeneous canopies in order to understand the canopy architecture and soil effects. Threedimensional (3D) radiative transfer models enable the simulation of tree orchards accounting for each single scene component, separating pure vegetation, soil and shadows (Zarco-Tejada et al., 2004; Suárez et al., 2007). Nevertheless, such 3D modelling approach for open canopies is rare in the thermal domain due to limited theoretical models available. The discrete anisotropic radiative transfer model (DART) (Gastellu-Etchegorry et al., 1996) was developed at first for the short-wavedomain, being successfully tested against reflectance measurements (Gastellu-Etchegorry et al., 1999) and applied to obtain forest canopy chemistry from remote sensing data (Gastellu-Etchegorry and Bruniquel-Pinel, 2001). Current DART model capability includes the thermal domain (Guillevic et al., 2003), simulating the propagation and the interactions within the canopy three-dimensional architecture of thermal infrared (TIR) radiation emitted by the cover components or incoming from the atmosphere.

This manuscript makes progress on assessing methods for the discrimination of irrigated and rainfed tree orchards, combining vegetation indices and thermal information obtained from ASTER imagery. A radiative transfer simulation conducted with DART model is used to simulate open orchards scenes, assessing the effects of the vegetation cover, crown LAI and background temperature on the canopy temperature used for discriminating between irrigated and rainfed orchards.

\section{Materials and methods}

\subsection{Study site description}

The experimental study was conducted in a $60 \mathrm{~km} \times 60 \mathrm{~km}$ area in southern Spain $\left(37^{\circ} 18^{\prime} \mathrm{N}, 4^{\circ} 42^{\prime} \mathrm{W}\right)$. The climate of the area is Mediterranean with an average annual rainfall of $447 \mathrm{~mm}$, concentrated from autumn to spring, and a reference annual evapotranspiration (ETo) of $1246 \mathrm{~mm}$. The area is located at $500 \mathrm{~m}$ altitude above sea level and generally flat. In this study area, 1076 olive orchards (Olea europaea L.) with different planting grid densities, and generally with bare soil between rows, were monitored between 2000 and 2006 years. The maximum slope observed for all fields used in this study was $28^{\circ}$, while the mean slope for all the olive orchards was $8^{\circ}$. A total of 134 olive orchards were irrigated using drip irrigation methods, and 942 olive orchards were non-irrigated (Fig. 1). Detailed information from the 1076 orchard fields monitored between 2000 and 2006 was obtained to conduct a large validation study, including field locations, field area, tree density, and irrigation type for each individual field over the 6-year period. An assessment conducted to study the relationship between orchard temperature and slope and geographical location indicated no statistic significance for such parameters, therefore not considering slope or orientation in further analyses in this study.

\subsection{ASTER imagery and auxiliary datasets}

Imagery of the study area was acquired with the ASTER, one of the 5 instruments onboard TERRA satellite launched by NASA in 1999. The sensor has 3 spectral bands in the visible near-infrared (VNIR), 6 bands in the short-wave-infrared (SWIR), and 5 bands in the TIR regions, with 15,30 , and $90 \mathrm{~m}$ ground resolution respectively. The images acquired over the 6 -year period for this study between 2000 and 2006 years included both summer and winter satellite acquisitions. The images were acquired at 11:30 GMT, corresponding to $13: 30$ and $12: 30 \mathrm{~h}$ local time for summer and winter, respectively. Meteorological data including air temperature for the date and time of each image acquisition were obtained from an automated meteorological station located within $30 \mathrm{~km}$ from the study area. These data were considered constant for all the study fields due to the generally flat area part of this study.

ASTER Level-1A imagery was processed applying radiometric and atmospheric correction methods. Radiometric coefficients and geolocation data were applied to obtain Level-1B imagery. Atsensor radiance was converted into top-of-atmosphere (TOA) reflectance using Eq. (1) (Chander and Markham, 2003):

$$
\rho_{P}=\frac{\Pi L_{\lambda} d^{2}}{\operatorname{ESUN}_{\lambda} \cos \theta_{S}}
$$

where $\rho_{P}$ is the reflectance, $L_{\lambda}$ the at-sensor spectral radiance, $d$ the earth-sun distance in astronomical units obtained from the astronomical ephemeredes, $\mathrm{ESUN}_{\lambda}$ the mean solar exoatmospheric irradiance, and $\theta_{S}$ is the solar zenith angle in degrees. $\operatorname{ESUN}_{\lambda}$ values were obtained from the extraterrestrial solar spectrum (nekwur) of the MODTRAN radiative transfer model (Berstein and Roberston, 1989) filtered for the VNIR ASTER bands. Atmospheric correction was conducted using MODTRAN and water vapor data acquired 


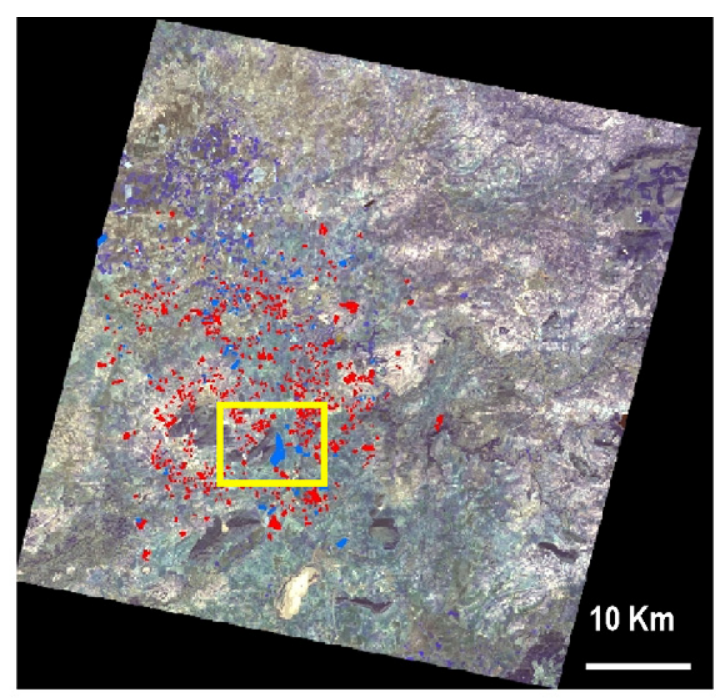

(a)

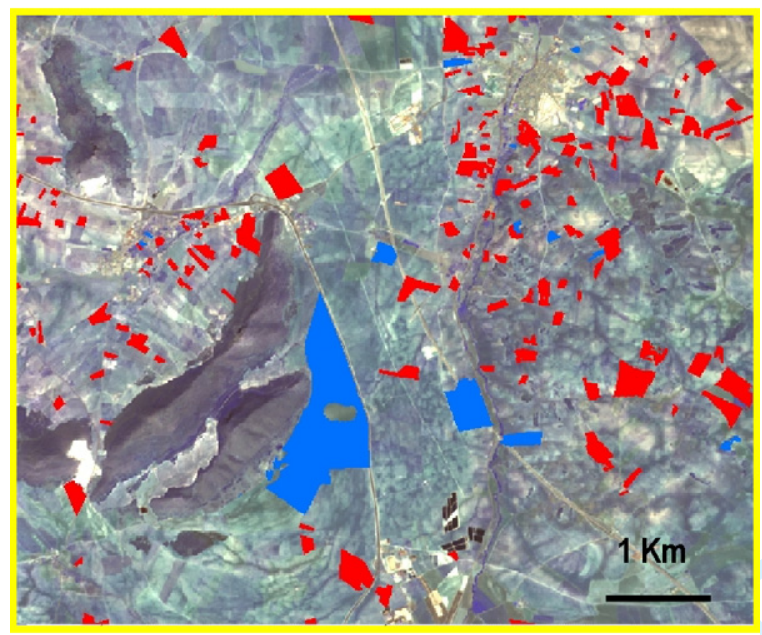

(b)

Fig. 1. (a) Image of the study area $\left(37^{\circ} 18^{\prime} \mathrm{N}, 4^{\circ} 42^{\prime} \mathrm{W}\right)$ acquired on 21 September 2005 with ASTER sensor. The irrigated olive fields are in blue color and the rainfed olive fields in red color; (b) close up of the study area shows a field selection of the experiment.

from the Aerosol Robotic Network (AERONET) station located $170 \mathrm{~km}$ from the study area.

Thermal bands were used for the retrieval of land surface temperature using the temperature and emissivity separation (TES) method (Gillespie et al., 1998). Two ASTER Temperature Standard Products (AST-08) scenes, summer and winter, were used to validate the retrieval of surface temperature from L1a products using the TES method for the rest of the ASTER dataset where AST08 data were not available (Fig. 2). The determination coefficients obtained were $r^{2}=0.99$ for 2001 image (Fig. 2a) and $r^{2}=0.87$ for June 2001 image (Fig. 2b), being the standard deviations obtained $0.1 \mathrm{~K}$ (March 2001) and $1.4 \mathrm{~K}$ (June 2001). Although $T_{\mathrm{s}}$ differences obtained between AST-08 and L1a calibration method for summer were $1.4 \mathrm{~K}$ for the entire scene, the comparison conducted for both scenes suggested a validity of the method used to estimate $T_{\mathrm{s}}$ using the TES method from the full database of L1a ASTER imagery used in this study.

Geographical location and identification for each study field were conducted by means of a vector map of the area using ArcGIS software (Environmental Systems Research Institute, Inc. (ESRI), USA) to extract image data for each individual orchard field under study. To avoid inaccuracies due to the different spatial resolutions for both ASTER imagery and the vector map, crop field attributes were extracted only from vectors overlapping at least $70 \%$ over an ASTER pixel. Vector intersection with the ASTER GRID dataset was conducted, removing pixels with intersected areas lower than $70 \%$. This approach was conducted individually for each crop field, removing a total of 300 orchards crop fields smaller than the $90 \mathrm{~m} \times 90 \mathrm{~m}$ ASTER pixel.

Due to the large heterogeneity found among orchards, with different planting grids, vegetation cover and LAI for each field, a criterion to compare field temperature among orchards was needed. Comparison between fields was conducted as function of crop cover percentage levels, therefore aiming at assessing the feasibility of detecting irrigated/rainfed fields with comparable soil and vegetation cover. Percentage vegetation cover was estimated for each field using the $0.5 \mathrm{~m}$ panchromatic ortho-rectified imagery collected over the entire area of study (Junta de Andalucía, 2005). The Interactive Data Language software (IDL) (ITT Corporation, NY, USA) was used to conduct an isodata classification (Tou and Gonzalez, 1974) on each single orchard, enabling the separation between soil and pure crown pixels (Fig. 3a-d). This methodology enabled the correct identification of pure tree crowns for each field under study, despite the different planting patterns. Fig. $3 e$ and $f$ shows the orthophotos acquired over the three orchard fields with different field size, soil color, planting pattern and percentage vegetation cover, showing the ASTER $10.657 \mu \mathrm{m}$ band (Band 13) acquired over the same fields.

Optical indices related to vegetation structure and condition (Zarco-Tejada et al., 2005) (Table 1) were used to study their potential to detect the effects of the irrigation type, including NDVI (Rouse et al., 1974), greenness index $(G), \mathrm{MTVI}_{1}$ (Haboudane et al., 2004), MCARI 1 (Haboudane et al., 2004), $\mathrm{MTVI}_{2}$ (Haboudane et al.,
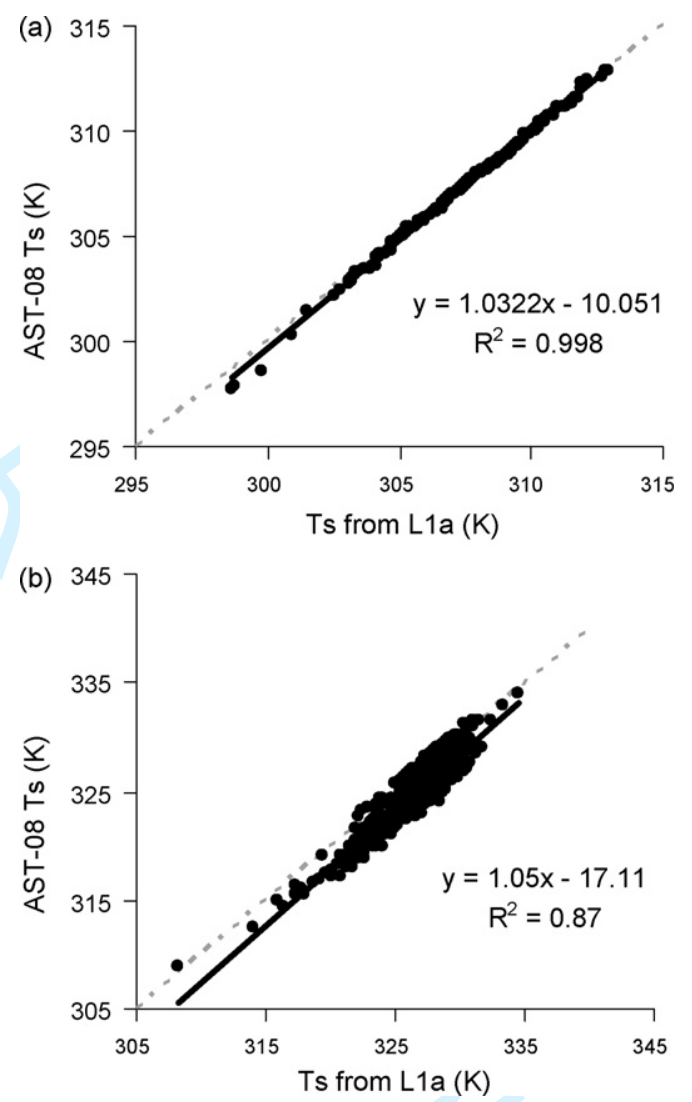

Fig. 2. Relationships obtained between land surface temperature (TES method) from L1a images and ASTER temperature standard product (AST-08) for (a) 12 March 2001 image and (b) 22 June 2001. 


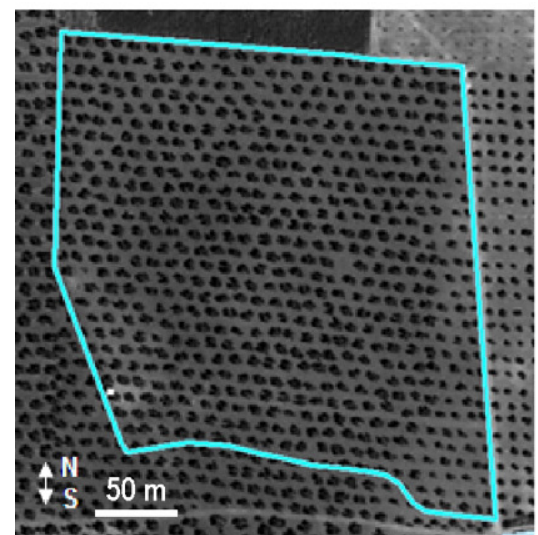

(a)

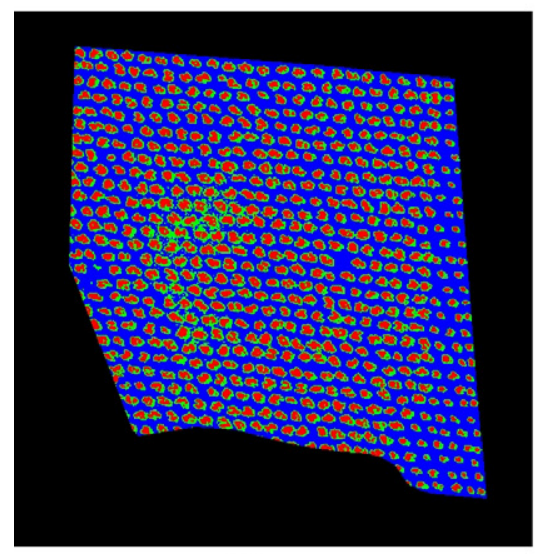

(c)

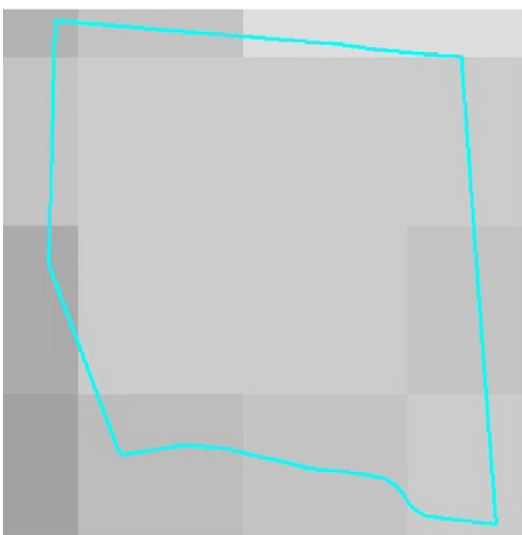

(e)

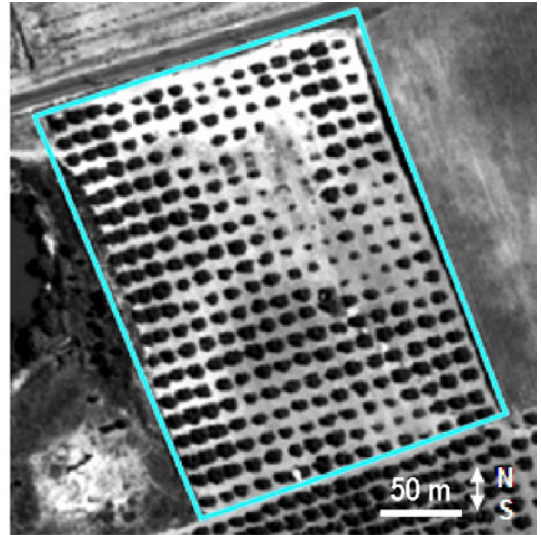

(b)

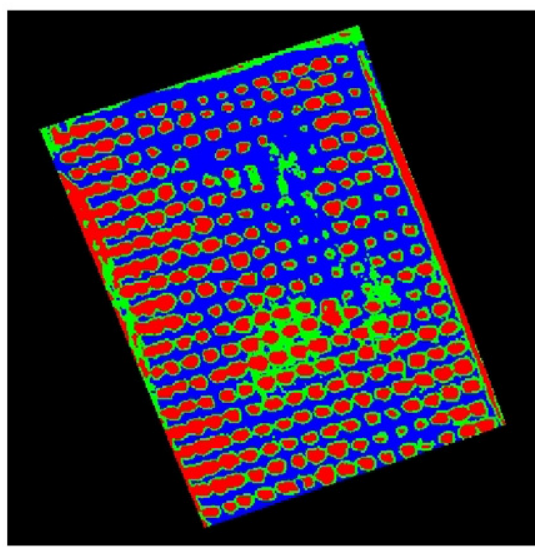

(d)

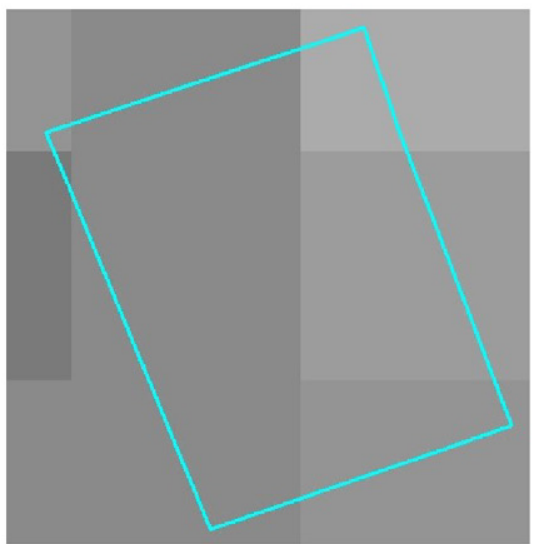

(f)

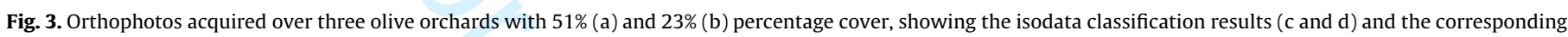
ASTER image (10.657 $\mu \mathrm{m}$ band) (e and $\mathrm{f}$ ).

Table 1

Vegetation indices used in this study.

\begin{tabular}{|c|c|c|}
\hline Vegetation index & Equation & Reference \\
\hline $\begin{array}{l}\text { Normalized difference vegetation index (NDVI) } \\
\text { Modified triangular vegetation index }\left(\mathrm{MTVI}_{1}\right)\end{array}$ & $\begin{array}{l}\mathrm{NDVI}=\left(R_{\mathrm{NIR}}-R_{\mathrm{red}}\right) /\left(R_{\mathrm{NIR}}+R_{\mathrm{red}}\right) \\
\mathrm{MTVI}_{1}=1.2 \times\left[1.2 \times\left(R_{800}-R_{550}\right)-2.5 \times\left(R_{670}-R_{550}\right)\right]\end{array}$ & $\begin{array}{l}\text { Rouse et al. (1974) } \\
\text { Haboudane et al. (2004) }\end{array}$ \\
\hline Modified triangular vegetation index $\left(\mathrm{MTVI}_{2}\right)$ & $\mathrm{MTVI}_{2}=\frac{1.5 \times\left[1.2 \times\left(R_{800}-R_{550}\right)-2.5 \times\left(R_{670}-R_{550}\right)\right]}{\sqrt{\left(2 \times R_{800}+1\right)^{2}-\left(6 \times R_{800}-5 \times \sqrt{R_{670}}\right)-0.5}}$ & Haboudane et al. (2004) \\
\hline Greenness index $(G)$ & $G=R_{554} / R_{677}$ & - \\
\hline Improved SAVI with self-adjustment factor L (MSAVI) & MSAVI $=\frac{1}{2}\left[2 \times R_{800}+1-\sqrt{\left(2 \times R_{800}+1\right)^{2}-8 \times\left(R_{800}-R_{670}\right)}\right]$ & Qi et al. (1994) \\
\hline $\begin{array}{l}\text { Optimized soil-adjusted vegetation index (OSAVI) } \\
\left.\text { Modified chlorophyll absorption in reflectance index (MCARI }{ }_{1}\right)\end{array}$ & $\begin{array}{l}\text { OSAVI }=(1+0.16) \times\left(R_{800}-R_{670}\right) /\left(R_{800}+R_{670}+0.16\right) \\
\text { MCARI }_{1}=1.2 \times\left[2.5 \times\left(R_{800}-R_{670}\right)-1.3 \times\left(R_{800}-R_{550}\right)\right]\end{array}$ & $\begin{array}{l}\text { Rondeaux et al. (1996) } \\
\text { Haboudane et al. (2004) }\end{array}$ \\
\hline Modified chlorophyll absorption in reflectance index (MCARI $\left.{ }_{2}\right)$ & MCARI $_{2}=\frac{1.5 \times\left[2.5 \times\left(R_{800}-R_{670}\right)-1.3 \times\left(R_{800}-R_{550}\right)\right]}{\sqrt{\left(2 \times R_{800}+1\right)^{2}-\left(6 \times R_{800}-5 \times \sqrt{R_{670}}\right)-0.5}}$ & Haboudane et al. (2004) \\
\hline
\end{tabular}


2004), MCARI 2 (Haboudane et al., 2004), MSAVI (Qi et al., 1994), and OSAVI (Rondeaux et al., 1996). These indices were calculated using the visible and near-infrared ASTER bands acquired over the same study sites in order to assess structural changes potentially caused by the irrigation type for each orchard field under study. Therefore, orchards were assessed for both surface temperature and structural vegetation indices over the 6 years.

\subsection{ASTER data analysis}

The mean field temperature was obtained from ASTER imagery as function of crop cover percentage intervals ranging between $15 \%$ and 55\%, assessing temperature differences for irrigated and rainfed orchards under similar vegetation cover levels. The field-tofield comparison considered a "success case" when an irrigated orchard yielded lower temperature and higher vegetation index (i.e. NDVI) than non-irrigated orchard under the same vegetation cover. Therefore, the fact under study claims that drip irrigated orchards yield lower crown temperature due to increased canopy conductance, and normally higher LAI, assuming similar vegetation cover within the ASTER pixel and similar soil temperature. In addition to field-to-field temperature comparisons conducted for all fields under the same vegetation cover level, the method was also conducted on orchards with the same NDVI and vegetation cover. This additional restriction was imposed to assess the feasibility of canopy temperature to detect thermal effects associated with field irrigation type independently from LAI effects.

A time-series cumulative index comprising ASTER orchard temperature minus air temperature $\left(T-T_{\mathrm{a}}\right)$ and NDVI was also assessed, adding the $\left(T-T_{\mathrm{a}}\right) / \mathrm{NDVI}$ information for the 6 -year ASTER imagery. The ratio $\left(T-T_{\mathrm{a}}\right) / \mathrm{NDVI}$ stresses the behavior of $T-T_{\mathrm{a}}$ and vegetation density as function of the irrigation type (i.e.

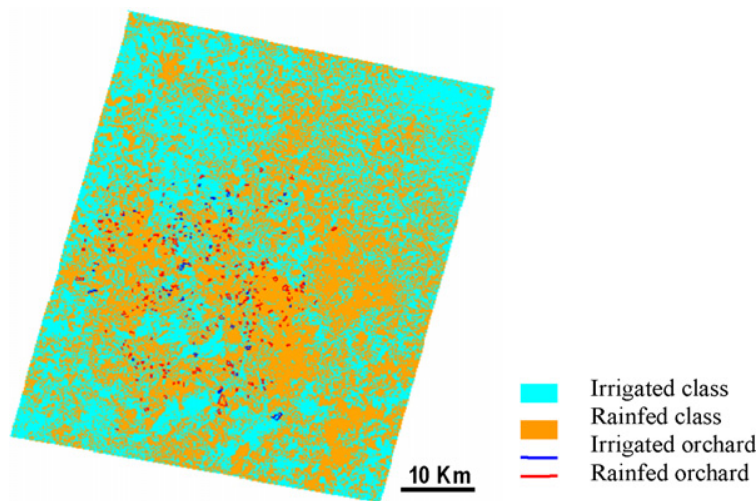

(a)

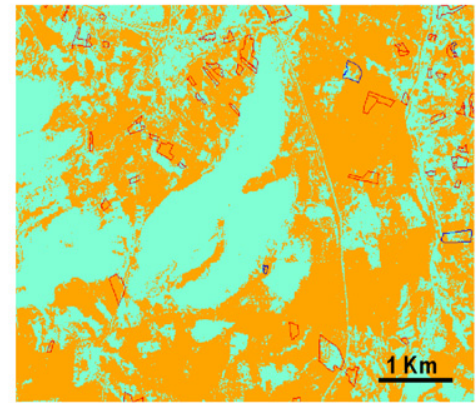

(b)

Fig. 4. (a) Mahalanobis distance classification conducted with the 6-year imagery series obtaining two classes: irrigated class (blue) and rainfed class (orange). Training irrigated orchards are shown in blue, and rainfed training orchards in red; (b) zoom of a particular classification image area irrigated/rainfed). The fact under study is that $\left(T-T_{\mathrm{a}}\right)$ is lower for irrigated orchards, while NDVI is higher due to more leaf area density. Combining thermal information with a vegetation index has been used in previously studies, showing that the slope of $T_{\mathrm{s}} /$ NDVI curve has been related to soil moisture (Goetz, 1997), stomatal conductance and evapotranspiration (Nemani and Running, 1989). The 6-year ASTER imagery database was used to compute the cumulative 6-year indices for each crop field, including $T$, NDVI and $\left(T-T_{\mathrm{a}}\right) /$ NDVI.

A supervised Mahalanobis distance classification was conducted using a summer ASTER image (6 July 2006), and the 6-year temporal ASTER series, using temperature, visible and near infrared bands to obtain two classes, irrigated and rainfed fields. Half of the irrigated and rainfed orchards were not considered to conduct the classification procedure, being used later for the validation of the results (Fig. 4), obtaining the confusion matrix. The same number of training and validation orchards was chosen for each vegetation cover.

The confusion matrix analysis enables the assessment of the accuracy as: (i) producer's accuracy, 1-(omission error), where omission error is the probability that the correct assignment is omitted for a particular pixel; (ii) user's accuracy, the number of pixels correctly mapped as this class in the image, including class overmapping due to commission errors (the probability that a particular class is assigned to the wrong pixel); and (iii) overall accuracy which is the number of pixels classified correctly dividing by the total number of pixels. The kappa coefficient $(\kappa)$, gives an overall accuracy assessment for the classification based on all classes commission and omission errors (Richards, 1994). The kappa coefficients generally range between +1 and -1 . A value of 1 indicates perfect agreement, a value of 0 indicates agreement purely by chance, and negatively values indicate less agreement than expected by chance alone.

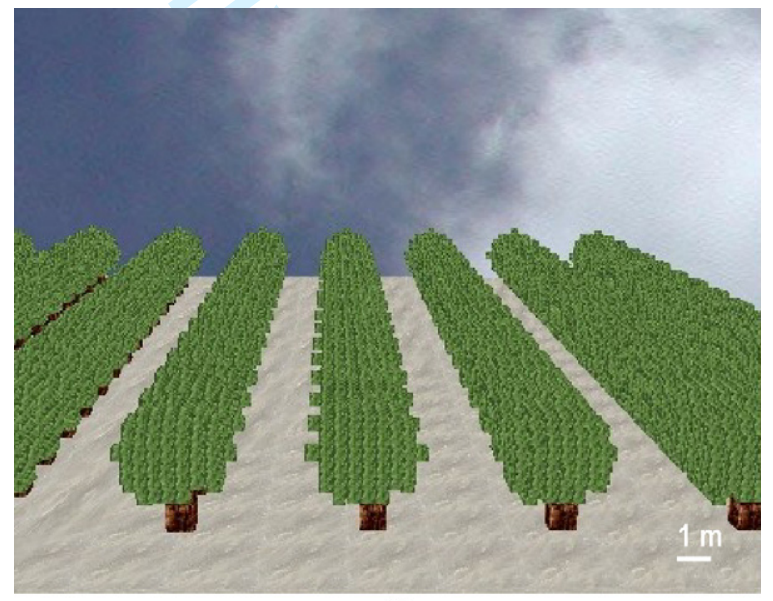

(a)

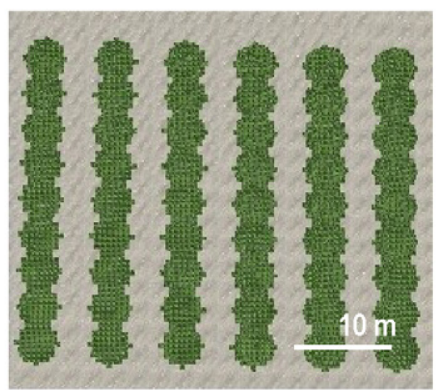

(b)

Fig. 5. 3D scene simulation of an olive grove using DART model: (a) front view and (b) nadir view. 
2.4. Simulation with DART radiative transfer model in the thermal domain

The radiative transfer model DART was used to simulate 3D scenes of olive groves to study the effects of different components (soil, vegetation and shadows) on the effective (pixel) temperature. DART can operate simulating reflectance or temperature, combining the ray tracing and the discrete ordinate methods. DART is designed to simulate different landscapes, comprising forest scenes with different tree types and scene components. DART uses a 3D matrix of cells containing the turbid material for simulating vegetation, and the opaque material for simulating surfaces such as ground, urban elements or trunks.

The inputs required for thermal DART simulations in this study were: (i) viewing geometry input parameters, including the azimuth and zenith solar angles; (ii) reflectance, maximum and minimum temperature of the different scene components (leaf, truck and soil) and leaf optical properties; (iii) structural parameters: cell and scene dimensions, number of trees in the scene, architecture of the trunk and the crown, and the spatial distribution of the trees. The output of the model is a 3D brightness temperature image. Fig. 5 shows an example of a 3D scene simulating an orchard with a typical pattern of an irrigated olive grove.

An assessment of DART model for simulating scenes of open tree orchards was conducted using diurnal airborne imagery acquired as part of the 2005 airborne campaign with the AHS (Sepulcre-Cantó et al., 2006; Sobrino et al., 2006). The AHS thermal imagery was acquired at 7:30, 9:30 and 12:30 GMT on 25 July 2005 over an olive orchard under different irrigation treatments applied in blocks of 12 trees where three drip irrigation treatments were randomly applied covering: (i) 100\% ET (well irrigated treatment, $R$ ); (ii) $25 \%$ ET (deficit treatment, S1); and (iii) $25 \%$ ET applied intermittently, with $43 \%$ ET from 14 June to 5 July and from 6 September to 19 October, stopping irrigation from 5 July to 6 September (deficit treatment, S2) (detailed information about the irrigation methods, and field and airborne data collection can be found in Sepulcre-Cantó et al. (2006). At each airborne flight time, air temperature, shaded and sunlit soil temperature, as well as pure crown temperature for trees under different irrigation treatments were monitored with a ground based Vaisala Weather

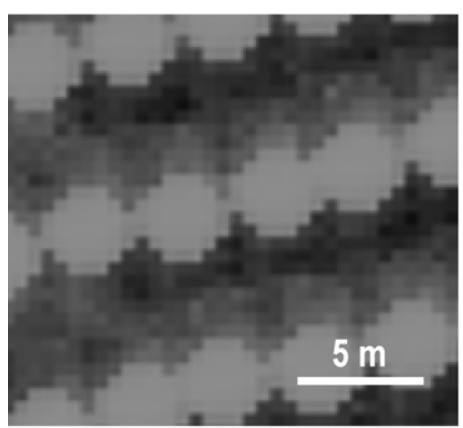

(a)

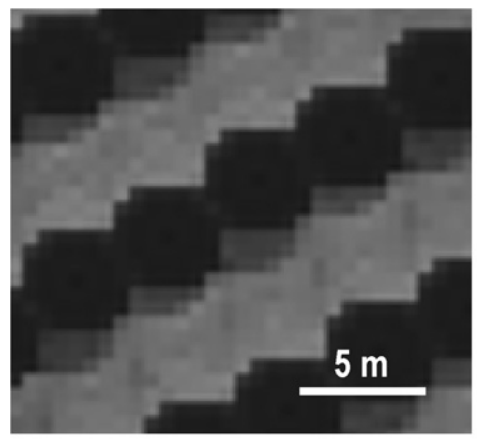

(c)

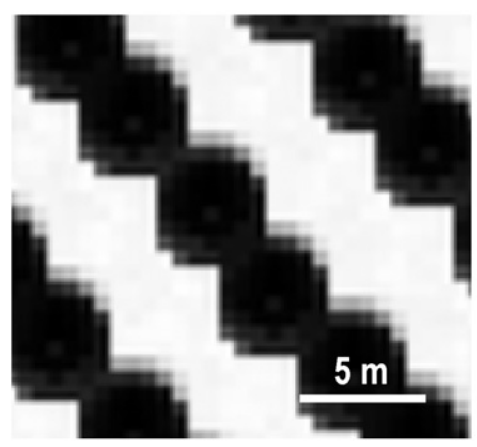

(e)

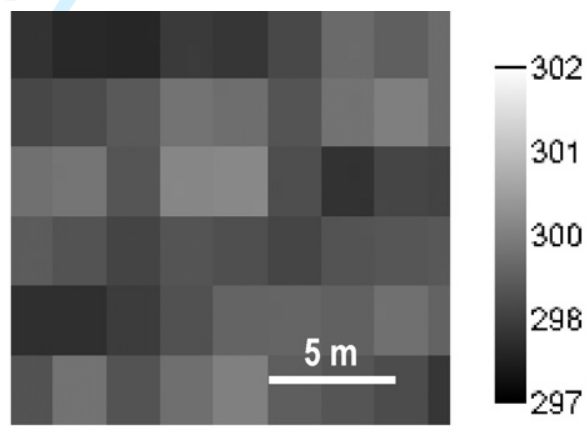

(b)

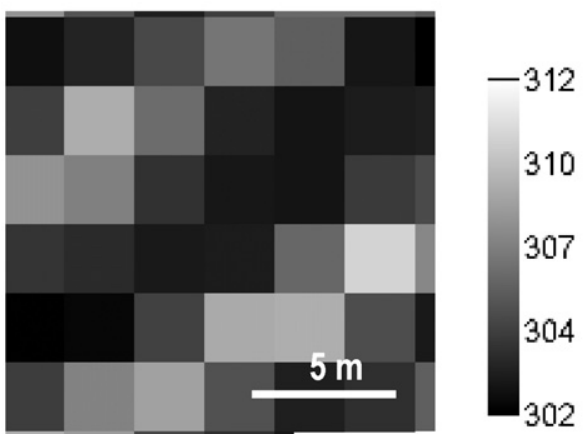

(d)

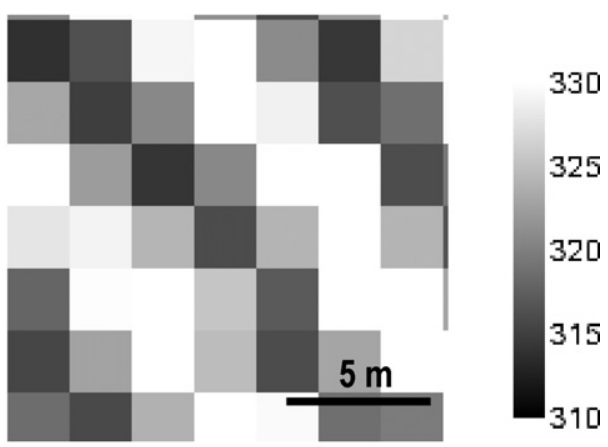

(f)

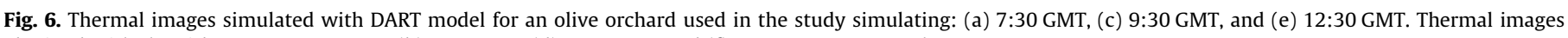
obtained with the airborne AHS sensor at (b) 7:30 GMT, (d) 9:30 GMT, and (f) 12:30 GMT on 25 July 2005. 


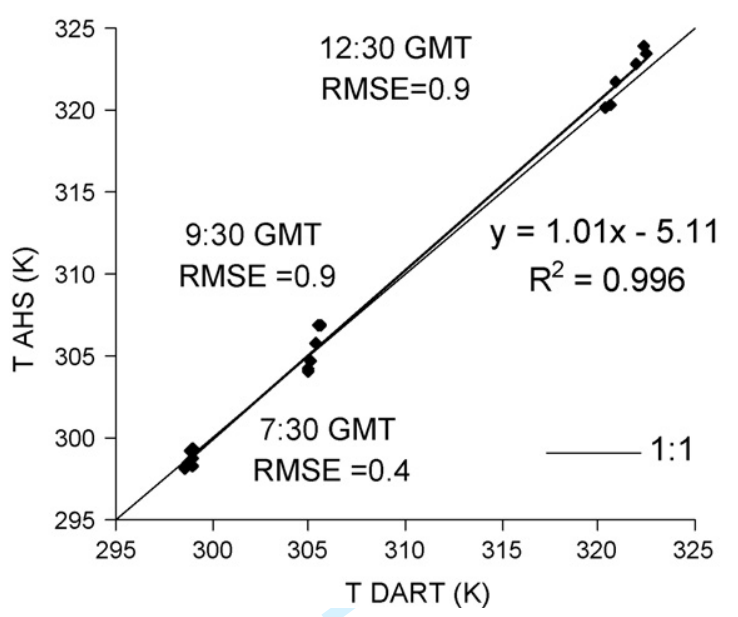

Fig. 7. Relationships obtained between DART-simulated temperature and thermal imagery acquired with the AHS sensor aggregated for the treatment blocks of the orchard used in the study at (a) 7:30 GMT; (b) 9:30 GMT, and (c) 12:30 GMT on 25 July 2005.

Transmitter (model WXT510, Vaisala Oyj, Helsinki, Finland) and IRTS infrared thermal sensors (model IRTS-P, Apogee, UT, USA). DART scenes for each AHS airborne overpass in the solar plane were computed, simulating the orchard temperature corresponding to each irrigation treatment block using model inputs from field IRTS instruments (Fig. 6). Azimuth and solar zenith angles for the flight times 7:30, 9:30 and 12:30 GMT on 25 July 2005 were used, as well as LAI and structural olive orchard measurements conducted in the field. Leaf optical parameters were set to those reported in Zarco-Tejada et al. (2004). Temperature of each scene component (sunlit soil, shadows and vegetation) obtained with the IRT sensors at each flight time was used. DART brightness temperature was obtained in monospectral mode for the default band comprising from 10 to $10.2 \mu \mathrm{m}$, running the model without atmospheric simulation. AHS brightness temperature was obtained for the 75 band (9.8-10.2 $\mu \mathrm{m})$, applying atmospheric correction to at-sensor information obtaining brightness surface temperature. Fig. 7 shows the relationship obtained between irrigation treatment block temperatures (effective temperature including crowns soil and shadows) simulated with DART model from external inputs acquired in the field, and those obtained with the AHS sensor for the three overflight times, obtaining RMSE values of $0.4,0.9$ and $0.9 \mathrm{~K}$ at $7: 30,9: 30$ and 12:30 GMT, respectively. The external inputs were mean values of leave temperatures, sunlit and shadow soil temperatures, tree LAI and tree volume. These results demonstrated the capability of DART model to aggregate scene components in open-canopy crops, a critical objective required for this study. A sensitivity analysis was conducted to assess the effects of scene components on the pixel temperature for different canopies. The effects of DART inputs on the potential differences expected between rainfed and irrigated olive orchards were assessed. The modelling study consisted on simulating orchards with varying percentage vegetation cover, crown LAI and soil temperatures, assessing the effects of crown temperature changes as a function of irrigation type on the aggregated pixel temperature that would be acquired by ASTER. Temperature differences between rainfed and irrigated leaves $\left(T_{\mathrm{lr}}-T_{\mathrm{li}}\right)$ were varied from 3 to $5 \mathrm{~K}$; those values were based on the observed datasets acquired over the 2 years with IRTS-P thermal sensors installed over olive trees. Different vegetation cover levels were obtained on these series of examples, varying the number of trees in the scene and the inter-distance between trees (grid pattern). Fig. 8 shows simulated nadir thermal images for an olive orchard with LAI $=3$ and 15\% (Fig. 8a), 35\% (Fig. 8b) and 55\%

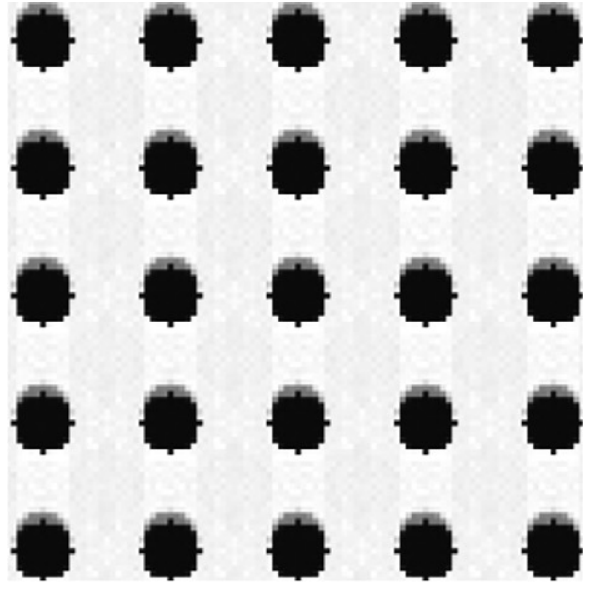

(a)

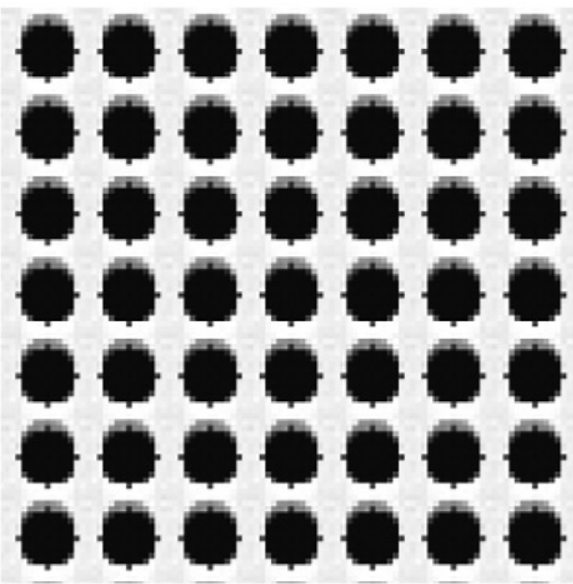

(b)

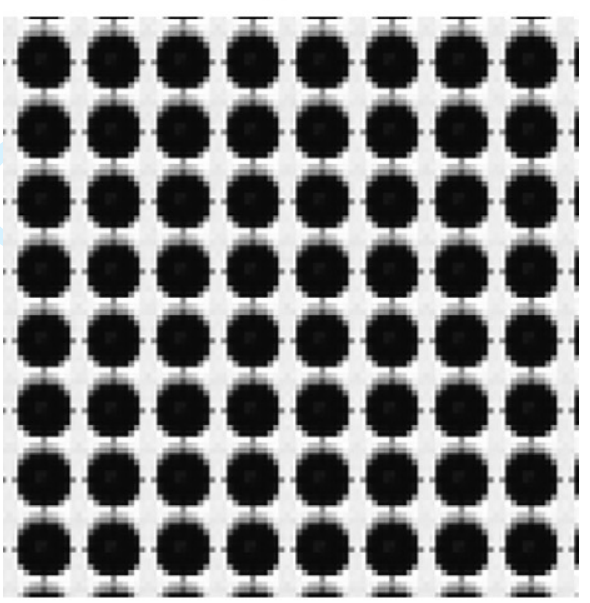

(c)

Fig. 8. Thermal images simulated with DART model for an olive orchard with (a) $15 \%$, (b) $35 \%$, and (c) $55 \%$ percentage cover.

(Fig. 8c) percentage cover. Azimuth and solar zenith angles for the ASTER overpass time (11:30 GMT) on 6 July 2006 were used. Trunk temperature was fixed as the air temperature, and the mean soil and leaf temperature were set to the one measured on the same day in the experimental study described earlier. Leaf temperatures were assumed constant for each crown, and reflectance and transmittance were assumed those given by the model for thermal domain. The DART model was run in monospectral mode with a single band from 10 to $10.2 \mu \mathrm{m}$ obtaining image brightness 
temperature as output. Table 2 shows the nominal values used for different inputs required to build the 3D scenes with DART simulations, as well as the range interval for the parameters used in the analysis conducted in this study.

Finally, a simulation study was conducted to assess the relationships between crown temperature and pixel temperature in summer and winter. The objective was to assess the offset found between pixel temperature (aggregated information from vegetation and shaded/sunlit soil) and crown temperature (pure crowns) as function of percentage cover. Crown temperature minus air temperature $\left(T_{\mathrm{c}}-T_{\mathrm{a}}\right)$ was varied between 1 and $5 \mathrm{~K}$ in summer, and between -2 and $2 \mathrm{~K}$ in winter, as observed on datasets acquired over 2 years with IRTS-P thermal sensors installed over olive trees. Soil temperature minus air temperature $\left(T_{\text {soil }}-T_{\mathrm{a}}\right)$ was obtained at 11:30 GMT (time of ASTER overpass) from the study site where thermal sensors were permanently installed. Table 3 shows the nominal values and range used in the simulation study.

\section{Results}

\subsection{ASTER temperature analysis for discriminating irrigated and rainfed orchards}

Mean orchard temperature for different crop cover percentage intervals showed differences between irrigated and rainfed fields (Fig. 9). The assessment was conducted for winter and summer images to study the crop temperature differences at the time of maximum and minimum seasonal water availability. Irrigated orchards in summer showed lower temperature values than rainfed orchard fields under the same percentage cover, while winter analysis showed smaller temperature differences potentially due to equal transpiration levels. Temperature differences between irrigated and rainfed orchards in summer yielded up to $2 \mathrm{~K}$ for orchards with percentage cover ranging between $20 \%$ and $30 \%$ (Fig. 9a and b). Comparable results were found in summer: on 21 September 2005 and 6 July 2006 ASTER images. Fig. 9c and d shows that mean temperature differences almost disappear for winter images (12 December 2000 and 2 January 2002), even existing an inversion of relationship. This is an important finding considering the large effects of bare soil temperature typical of open canopies on the ASTER pixel size. Additionally, drip irrigation methods used in the fields under study would not wet the soil observed in the aggregated ASTER pixel. Consistently, fields with
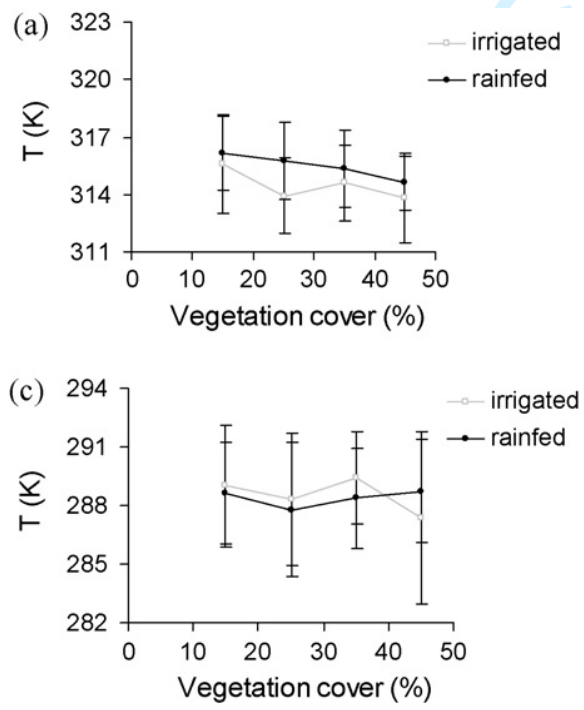

Table 2

Nominal values and range of parameters used for the olive grove DART simulation study.

\begin{tabular}{|c|c|}
\hline Direction input parameters & Nominal values and range \\
\hline Sun zenit angle $\left(^{\circ}\right)$ & 165.4 \\
\hline Sun azimut angle $\left({ }^{\circ}\right)$ & 184.7 \\
\hline \multicolumn{2}{|l|}{ Scattering properties and temperatures } \\
\hline Trunk reflectance & 0.03 \\
\hline Trunk $T_{\min }(\mathrm{K})$ & 305 \\
\hline Trunk $T_{\max }(\mathrm{K})$ & 305 \\
\hline Soil reflectance & 0.05 \\
\hline Soil $T_{\min }(\mathrm{K})$ & $212-324$ \\
\hline Soil $T_{\max }(\mathrm{K})$ & $322-334$ \\
\hline Leaf dimension (m) & 0.01 \\
\hline Leaf adaxial reflectance & 0.01 \\
\hline Leaf abaxial reflectance & 0.01 \\
\hline Leaf transmitance & 0.01 \\
\hline Leaf $T_{\min }(\mathrm{K})$ & $306-311$ \\
\hline Leaf $T_{\max }(\mathrm{K})$ & $306-311$ \\
\hline \multicolumn{2}{|l|}{ Structural parameters } \\
\hline Cell dimensions $(x, y, z)(\mathrm{m})$ & 0.5 \\
\hline Scene dimensions $(x, y)(\mathrm{m})$ & 90 \\
\hline Number of trees & $64-224$ \\
\hline Mean trunk height below crown (m) & 1 \\
\hline Trunk height within crown (m) & 1 \\
\hline Trunk diameter within the tree crown (m) & 1 \\
\hline Mean trunk diameter below crown (m) & 1 \\
\hline Crown height $(\mathrm{m})$ & 5 \\
\hline LAI & $1-6$ \\
\hline Inter-trees distance $(\mathrm{d} x)(\mathrm{m})$ & $8-11$ \\
\hline Inter-trees distance $(\mathrm{d} y)(\mathrm{m})$ & $8-11$ \\
\hline Crown ellipsoid first axis (m) & 5 \\
\hline Crown ellipsoid second axis (m) & 5 \\
\hline
\end{tabular}

lower percentage cover in summer showed higher temperature values for both irrigated and rainfed orchards due to the soil influence. Differences between soil and olive tree temperature yielded up to $20 \mathrm{~K}$ (Sepulcre-Cantó et al., 2006), therefore causing large effects on canopy temperature for pixels with a low percentage cover.

As described, irrigated orchards generally showed lower temperatures than rainfed orchard fields for the same percentage cover except in winter. However, the same percentage cover could lead to differences in vegetation densities, as it would be expected on irrigated orchards that generally yield higher leaf area densities
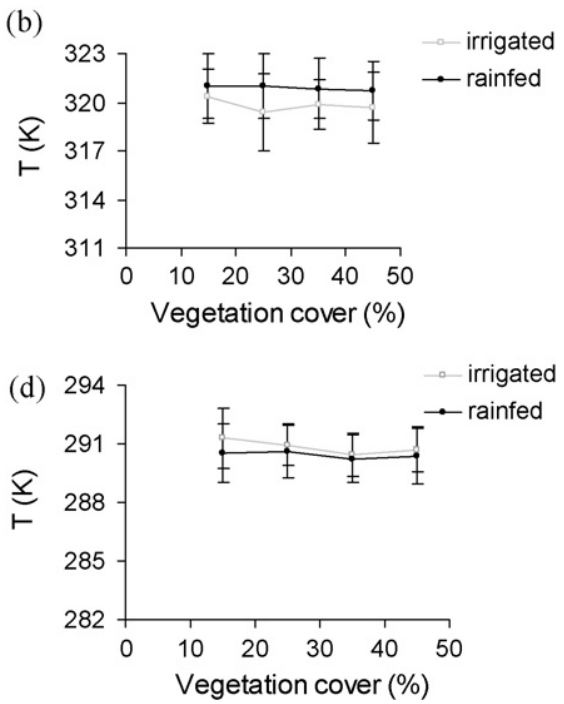

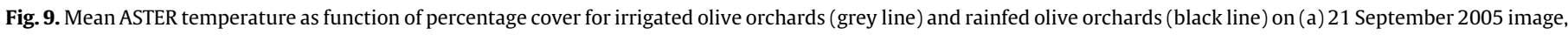
(b) 6 July 2006 image, (c) 12 December 2000 image and (d) 2 January 2002 image. 
than rainfed tree crowns. Therefore, a careful comparison of thermal differences for fields with similar both percentage cover and vegetation density was needed using combined temperature, percentage cover and NDVI indicators.

\subsection{Combining temperature and vegetation indices for detecting irrigated and rainfed orchards}

The objective of this part of the study was to evaluate the capability of temperature and vegetation indices to assess the discrimination of irrigated and rainfed orchards. All field-to-field comparisons between irrigated and rainfed orchards with same percentage cover were evaluated, with a total of more than 2000 field-to-field comparisons. The number of cases yielding success or fail for the hypothesis that irrigated orchards yield lower temperature and higher vegetation index than rainfed orchards with same percentage cover was counted. Table 4 shows the percentage of success for temperature and for the different vegetation indices proposed in this study. All the proposed indices were capable of detecting consistent differences between rainfed and irrigated olive orchards. $\mathrm{MTVI}_{2}$ and $\mathrm{MCARI}_{2}$ indices, which are more resistant to soil influence, obtained lightly better results than the rest of vegetation indices (Table 4).

A further restriction was applied to minimize the effects caused by different vegetation densities (LAI) in the pixel temperature at the ASTER resolution (especially important for open crops). Both NDVI and the percentage cover were fixed in the test conducted to compare irrigated and rainfed orchard temperatures (Table 4). Even under these restrictive conditions of orchard comparisons under the same percentage cover and NDVI, orchard temperature was able to detect some differences between irrigated and rainfed orchards in summer, decreasing in winter. Fig. 10 shows an example of two orchards with the same vegetation percentage cover (25\%) and same NDVI (0.18) and their corresponding ASTER temperature distribution obtained on 6 July 2006. In such example, mean temperature difference between these two orchards yielded
Table 3

Nominal values and range of parameters used for the comparison between $T_{\mathrm{c}}$ and $T_{\text {pixel }}$ DART simulation study.

\begin{tabular}{|c|c|c|}
\hline \multirow[t]{2}{*}{ Direction input parameters } & \multicolumn{2}{|c|}{ Nominal values and range } \\
\hline & $\begin{array}{l}\text { Summer } \\
\text { simulation }\end{array}$ & $\begin{array}{l}\text { Winter } \\
\text { simulation }\end{array}$ \\
\hline Sun zenit angle $\left({ }^{\circ}\right)$ & 165.4 & 119 \\
\hline Sun azimut angle $\left({ }^{\circ}\right)$ & 184.7 & 168 \\
\hline \multicolumn{3}{|l|}{ Scattering properties and temperatures } \\
\hline Trunk reflectance & 0.03 & 0.03 \\
\hline Trunk $T_{\min }(\mathrm{K})$ & 301.45 & 287.75 \\
\hline Trunk $T_{\max }(\mathrm{K})$ & 301.45 & 287.75 \\
\hline Soil reflectance & 0.05 & 0.05 \\
\hline Soil $T_{\min }(\mathrm{K})$ & 320.45 & 283.55 \\
\hline Soil $T_{\max }(\mathrm{K})$ & 330.45 & 293.55 \\
\hline Leaf dimension $(\mathrm{m})$ & 0.01 & 0.01 \\
\hline Leaf adaxial reflectance & 0.01 & 0.01 \\
\hline Leaf abaxial reflectance & 0.01 & 0.01 \\
\hline Leaf transmitance & 0.01 & 0.01 \\
\hline Leaf $T_{\min }(\mathrm{K})$ & $302.45-306.45$ & $285.75-289.75$ \\
\hline Leaf $T_{\max }(\mathrm{K})$ & $302.45-306.45$ & $285.75-289.75$ \\
\hline \multicolumn{3}{|l|}{ Structural parameters } \\
\hline Cell dimensions $(x, y, z)(\mathrm{m})$ & 0.5 & 0.5 \\
\hline Scene dimensions $(x, y)(\mathrm{m})$ & 90 & 90 \\
\hline Number of trees & 64-186 & 64-186 \\
\hline $\begin{array}{l}\text { Mean trunk height below } \\
\text { crown }(\mathrm{m})\end{array}$ & 1 & 1 \\
\hline Trunk height within crown (m) & 1 & 1 \\
\hline $\begin{array}{l}\text { Trunk diameter within the tree } \\
\text { crown }(\mathrm{m})\end{array}$ & 1 & 1 \\
\hline Mean trunk diameter below crown (m) & 1 & 1 \\
\hline Crown height $(\mathrm{m})$ & 5 & 5 \\
\hline LAI & 2 & 2 \\
\hline Inter-trees distance $(\mathrm{d} x)(\mathrm{m})$ & $8-11$ & $8-11$ \\
\hline Inter-trees distance $(\mathrm{d} y)(\mathrm{m})$ & $8-11$ & $8-11$ \\
\hline Crown ellipsoid first axis (m) & 5 & 5 \\
\hline Crown ellipsoid second axis (m) & 5 & 5 \\
\hline
\end{tabular}

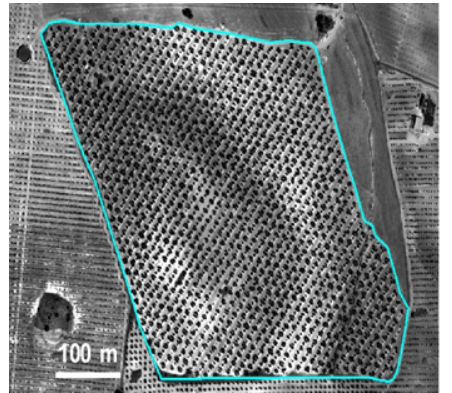

(a)

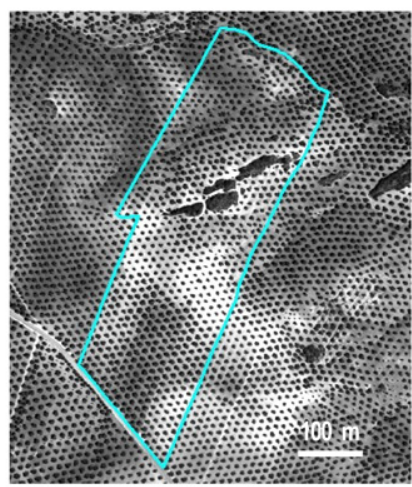

(c)

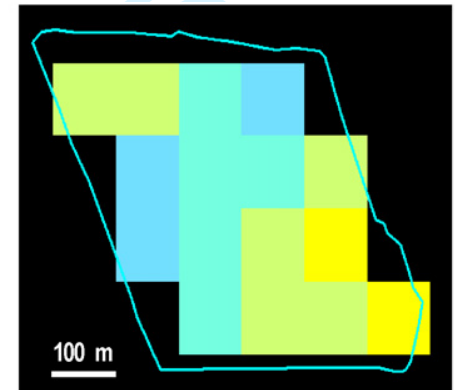

(b)

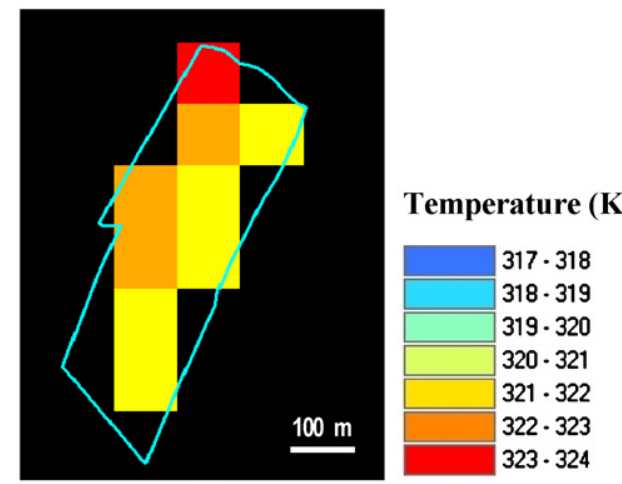

(d)

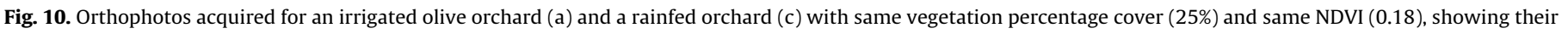
corresponding ASTER temperature images (b and d). 


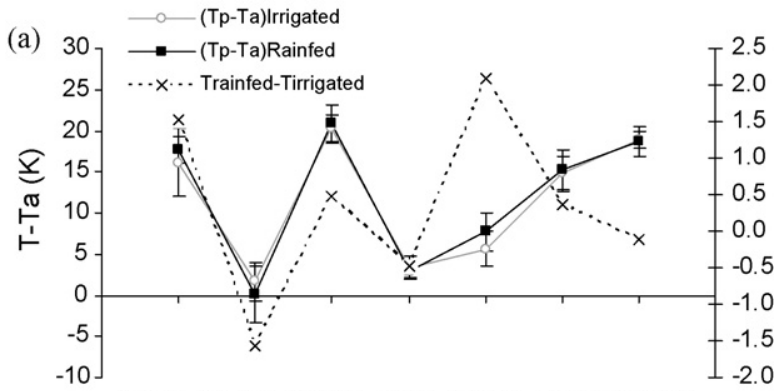

7/05/00 12/12/00 22/06/01 1/02/02 25/04/03 21/09/057/06/06

Date
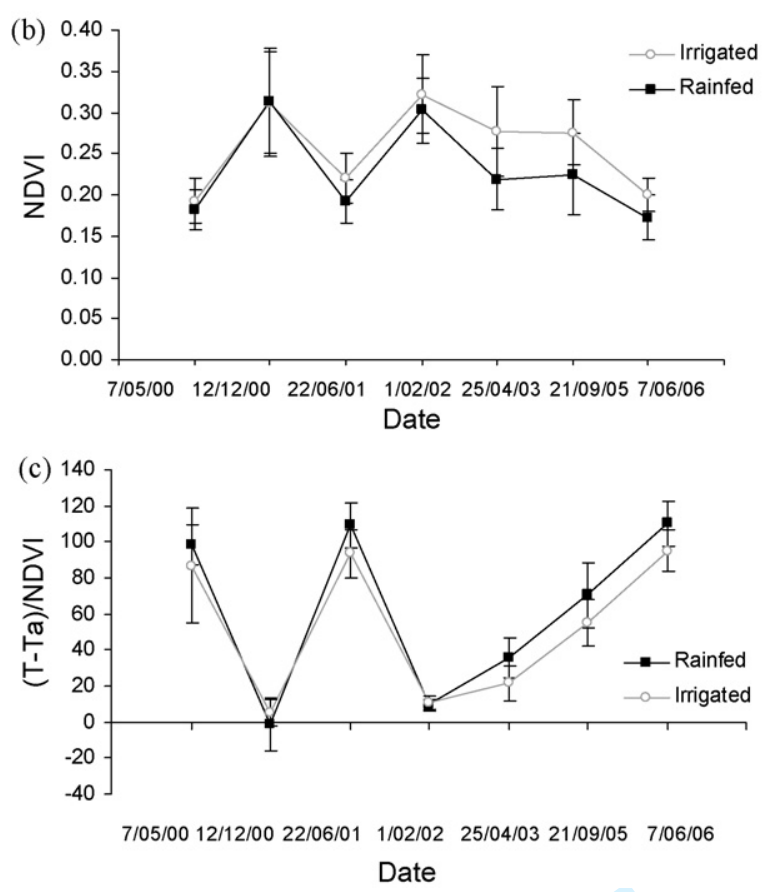

Fig. 11. Variation of mean canopy temperature (a), mean NDVI (b), and mean $\left(T-T_{\mathrm{a}}\right)$ /NDVI (c) values over the study period for the irrigated and (grey line) rainfed (black line) orchards with percentage covers between $24 \%$ and $25 \%$.

$2 \mathrm{~K}$, differences that could be associated with irrigated (Fig. 10a and $\mathrm{b}$ ) and non-irrigated (Fig. 10c and d) condition.

The variation of temperature, NDVI and $\left(T-T_{\mathrm{a}}\right) / \mathrm{NDVI}$ for the entire ASTER time-series (Fig. 11), shows the mean values of the irrigated and rainfed orchards with percentage cover ranges between $24 \%$ and $25 \%$ ( 29 orchards, 9 of them irrigated). It can be

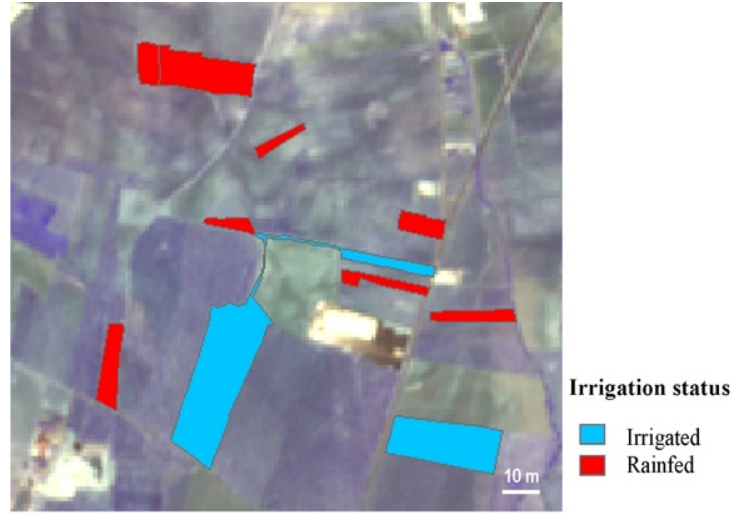

(a)

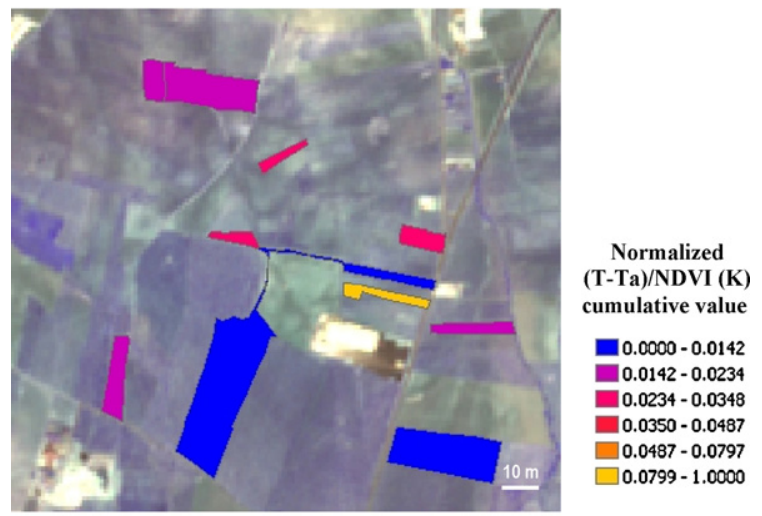

(b)

Fig. 12. (a) Irrigated (blue) and rainfed (red) orchards over the study area acquired on 21 September 2005 with ASTER sensor; (b) normalized cumulative $\left(T-T_{\mathrm{a}}\right)$ /NDVI value calculated for each field over the entire study period.

seen that rainfed orchards had higher temperature values than irrigated orchards for spring and summer images yielding $2 \mathrm{~K}$ differences, while these differences disappeared in winter. Consistently, the NDVI for the irrigated orchards obtained higher values than rainfed fields for all the study period. Results indicate that the combined $\left(T-T_{\mathrm{a}}\right) / \mathrm{NDVI}$ index strengthen the properties of both temperature and NDVI to assess differences between irrigated and rainfed orchards.

Cumulative values for the full period comprising 6 years of temperature, NDVI and $\left(T-T_{\mathrm{a}}\right)$ /NDVI from ASTER imagery were obtained (Table 4$)$. The cumulative $\left(T-T_{\mathrm{a}}\right.$ )/NDVI was the best indicator to detect differences between irrigated and non-irrigated orchards, yielding a $78 \%$ of success percentage in agreement with the

Table 4

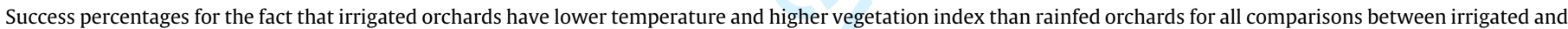
rainfed orchards with the same percentage cover.

\begin{tabular}{|c|c|c|c|c|c|c|c|c|}
\hline \multirow[t]{2}{*}{ Parameter } & \multicolumn{8}{|c|}{ Success percentage (\%) } \\
\hline & $05 / 07 / 2000$ & $12 / 12 / 2000$ & $22 / 06 / 2001$ & $02 / 01 / 2002$ & $25 / 04 / 2003$ & $21 / 09 / 2005$ & $06 / 07 / 2006$ & Cumulative value \\
\hline $\mathrm{MTVI}_{1}$ & 66 & 47 & 71 & 52 & 66 & 78 & 76 & \\
\hline $\mathrm{MTVI}_{2}$ & 68 & 47 & 72 & 54 & 67 & 78 & 77 & \\
\hline G & 62 & 49 & 62 & 61 & 63 & 67 & 68 & \\
\hline MSAVI & 65 & 47 & 73 & 49 & 66 & 78 & 74 & \\
\hline OSAVI & 64 & 47 & 73 & 52 & 67 & 78 & 76 & \\
\hline MCARI $_{1}$ & 66 & 47 & 71 & 52 & 66 & 78 & 76 & \\
\hline $\mathrm{MCARI}_{2}$ & 68 & 47 & 72 & 54 & 67 & 78 & 77 & \\
\hline$T$ (NDVI fixed) & 57 & 38 & 65 & 41 & 65 & 65 & 62 & \\
\hline NDVI & 62 & 47 & 72 & 58 & 72 & 76 & 76 & 68 \\
\hline$T-T_{\mathrm{a}}$ & 52 & 48 & 55 & 39 & 58 & 60 & 58 & 61 \\
\hline$\left(T-T_{\mathrm{a}}\right) / \mathrm{NDVI}$ & 65 & 45 & 72 & 41 & 68 & 77 & 74 & 78 \\
\hline
\end{tabular}



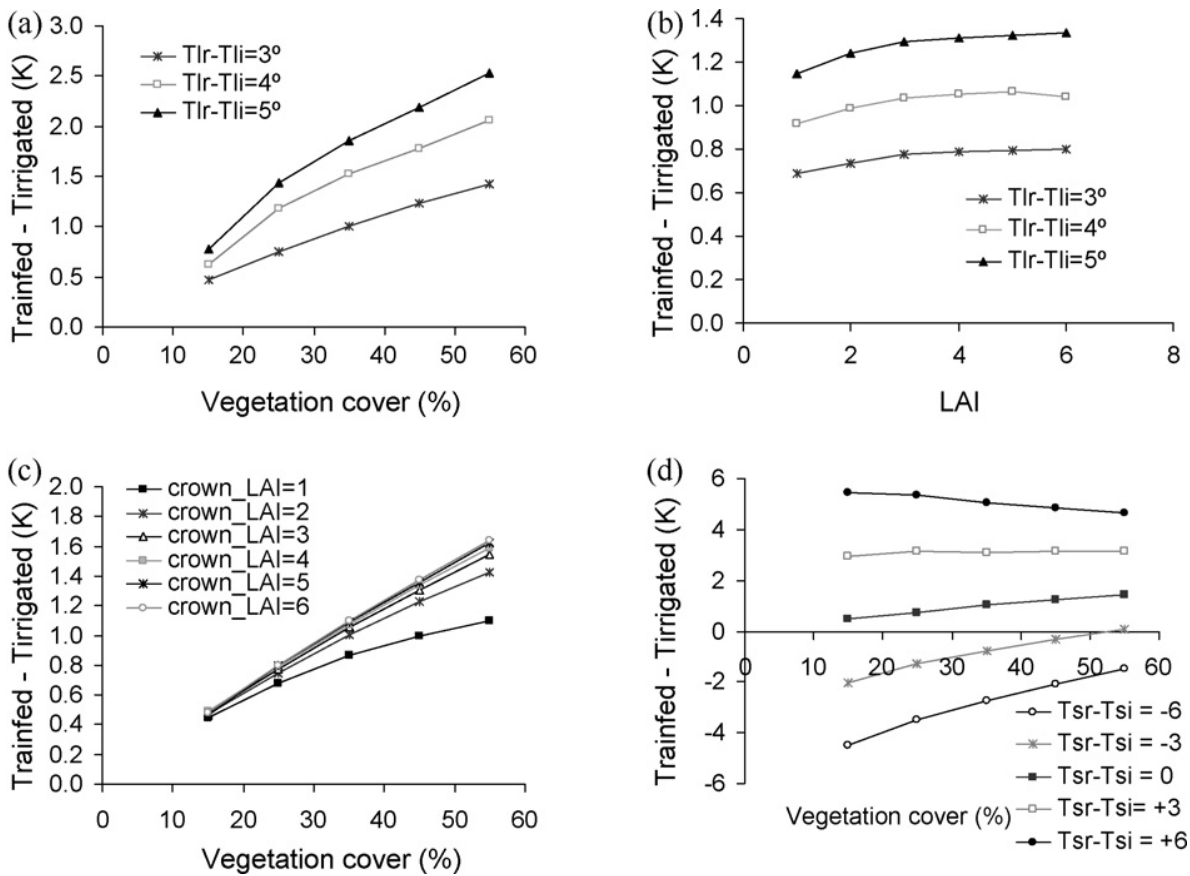

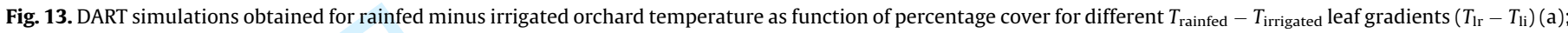

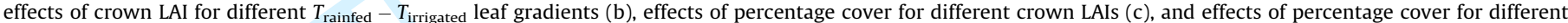
$T_{\text {rainfed }}-T_{\text {irrigated }}$ soil gradients $\left(T_{\mathrm{sr}}-T_{\mathrm{si}}\right)(\mathrm{d})$.

fact that irrigated orchards would have lower combined $\left(T-T_{\mathrm{a}}\right) /$ NDVI ratio than rainfed orchards. Moreover, results shown in Table 4 demonstrate the improvement obtained to discriminate between irrigated and rainfed orchards using an ASTER time-series instead of information provided from a single ASTER image. Fig. 12 shows an ASTER image over an area with irrigated and rainfed orchards (Fig. 12a) and their corresponding normalized $\left(T-T_{\mathrm{a}}\right) / \mathrm{NDVI}$ cumulative value (Fig. 12b) for the entire ASTER time-series period. The cumulative index was normalized between 0 and 1 , showing that orchards with lower cumulative values corresponded to irrigate orchards. However, careful use of this parameter is needed to identify irrigated and rainfed orchards, requiring making the comparisons under the same levels of vegetation percentage cover.
Tables 5 and 6 show the confusion matrix resulting from the supervised classification method conducted using the visible, near infrared and temperature information for one summer image (Table 5) and for the complete 6-year series of ASTER imagery (Table 6). Accuracies for identified irrigated and rainfed olive orchards using one summer image (6 July 2006) are shown in Table 5, obtaining 51\% for irrigated and $69 \%$ for rainfed class in producer's accuracy, and $28 \%$ for irrigated and $86 \%$ for rainfed in user's accuracy. The kappa obtained was 0.16 with an overall accuracy of $66 \%$. These single-image classification results were improved using the entire 6-year ASTER imagery series (Table 6). The results obtained for the entire ASTER series were $65 \%$ and $76 \%$ in producer's accuracy for irrigated and rainfed classes respectively,

Table 5

Confusion matrix for the Mahalanobis distance classification using the ASTER image on 6 July 2006.

\begin{tabular}{|c|c|c|c|c|}
\hline \multirow{2}{*}{$\begin{array}{l}\text { Mahalanobis distance classification } \\
\text { Class }\end{array}$} & \multicolumn{4}{|c|}{ Ground-truth } \\
\hline & Irrigated & Rainfed & Total & Users accuracy (\%) \\
\hline Irrigated & 4964 & 12,896 & 17,860 & 27.79 \\
\hline Rainfed & 4667 & 29,058 & 33,725 & 86.16 \\
\hline Total & 9631 & 41,954 & 51,585 & \\
\hline Producer's accuracy (\%) & 51.54 & 69.26 & & Overall accuracy $=65.95 \%$; kappa $\kappa=0.16$ \\
\hline
\end{tabular}

Table 6

Confusion matrix for the Mahalanobis distance classification using the 6-year ASTER imagery series.

\begin{tabular}{|c|c|c|c|c|}
\hline \multirow{2}{*}{$\begin{array}{l}\text { Mahalanobis distance classification } \\
\text { Class }\end{array}$} & \multicolumn{4}{|c|}{ Ground-truth } \\
\hline & Irrigated & Rainfed & Total & Users accuracy (\%) \\
\hline Irrigated & 6375 & 9,839 & 16,214 & 39.32 \\
\hline Rainfed & 3359 & 32,324 & 35,683 & 90.59 \\
\hline Total & 9734 & 42,163 & 51,897 & \\
\hline Producer's accuracy (\%) & 65.49 & 76.66 & & Overall accuracy $=74.57 \%$; kappa $\kappa=0.34$ \\
\hline
\end{tabular}


and 39\% for irrigated and 91\% for the rainfed class in user's accuracy. In this case, kappa was 0.34 with an overall accuracy of $75 \%$.

\subsection{Simulating canopy temperature with DART on open canopies}

The previous results obtained with ASTER thermal imagery under different percentage cover, LAI and soil conditions were compared with simulations conducted with DART radiative transfer model in the thermal domain. The simulation study conducted with DART was focused on assessing the thermal effects of vegetation percentage cover, LAI and soil temperature on ASTER pixel temperature (Fig. 13). In particular, simulations assessed the potential thermal differences between rainfed and irrigated orchards as function of the mentioned canopy and soil characteristics. Fig. 13a shows the variation of the differences between rainfed and irrigated orchard temperature as function of the vegetation percentage cover, assuming leaf temperature differences between irrigated and rainfed cases ranging between 3 and $5 \mathrm{~K}$. Consistently, it can be noticed that differences between rainfed and irrigated orchard temperature increases with the vegetation cover level. This is due to lower soil effects on pixel temperature at larger percentage cover. Differences between rainfed and irrigated pixels varied between $0.5 \mathrm{~K}$ (15\% percentage cover) and $1.5 \mathrm{~K}$ (55\% percentage cover) for leaf thermal differences (between rainfed and irrigated) of $3 \mathrm{~K}$, and between $0.8 \mathrm{~K}$ (15\% percentage cover) and $2.5 \mathrm{~K}(55 \%$ percentage cover) for leaf thermal differences of $5 \mathrm{~K}$. These results obtained through DART simulation agreed with those observed in the experimental study with ASTER imagery on 6 July 2006 (Fig. 9b), in which differences between irrigated and rainfed crop fields were $0.6 \mathrm{~K}$ for $15 \%$ percentage cover, and $1.1 \mathrm{~K}$ for $45 \%$ percentage cover.

To study the LAI effects on the temperature difference between rainfed and irrigated orchards at ASTER resolution, the assessment consisted on ranging crown LAI between 1 and 6 , and leaf temperature differences between 3 and $5 \mathrm{~K}$ (Fig. 13b). Temperature differences were assessed as well as function of percentage cover ranging between $15 \%$ and $55 \%$ for different crown LAI values (Fig. 13c). The differences found between rainfed and irrigated simulated temperatures were hardly dependent on LAI. For leaf temperature differences of $3 \mathrm{~K}, T_{\text {rainfed }}-T_{\text {irrigated }}$ difference ranged between $0.69 \mathrm{~K}(\mathrm{LAI}=1)$ and $0.80 \mathrm{~K}(\mathrm{LAI}=6)$ for percentage cover of $25 \%$. Nevertheless, LAI influenced $T_{\text {rainfed }}-T_{\text {irrigated }}$ for larger vegetation cover pixels (Fig. 13c). For low LAI pixels, differences between $T_{\text {rainfed }}$ and $T_{\text {irrigated }}$ were smaller (under $1 \mathrm{~K}$ for all the vegetation cover levels), due to larger effects caused by soil temperature on the aggregated ASTER pixel, diminishing the vegetation thermal differences. For all LAI cases, differences between irrigated and rainfed pixels become almost negligible for percentage covers lower than $15 \%$. Fig. 13d shows the simulated $T_{\text {rainfed }}-T_{\text {irrigated }}$ as function of vegetation cover for differences between rainfed and irrigated soil temperatures ranging between -6 and $+6 \mathrm{~K}$. This simulation assessment was conducted in order to evaluate the effects of different soil temperature levels on rainfed and irrigated orchards as a function of vegetation cover. As expected, soil temperature affects very much the difference between $T_{\text {rainfed }}$ and $T_{\text {irrigated }}$ on low percentage cover pixels. Differences yielded $5.4 \mathrm{~K}$ for $15 \%$ percentage cover, while $4.7 \mathrm{~K}$ were obtained for $55 \%$ percentage cover when the difference between rainfed and irrigated soil was $6 \mathrm{~K}$. On the other hand, results were $-4.5 \mathrm{~K}$ ( $15 \%$ percentage cover) and $-1.4 \mathrm{~K}(55 \%$ percentage cover) when the difference between rainfed and irrigated soil was $-6 \mathrm{~K}$. It can be noticed the trend converging at high percentage cover (Fig. 13d), although still showing large soil effects on pixel temperature as function of the soil temperature. For a 50\% vegetation cover, differences between canopy $T_{\text {rainfed }}$ and $T_{\text {irrigated }}$ became undetectable when $T_{\text {soil }}$ rainfed $-T_{\text {soil irrigated }} \leq-3 \mathrm{~K}$.
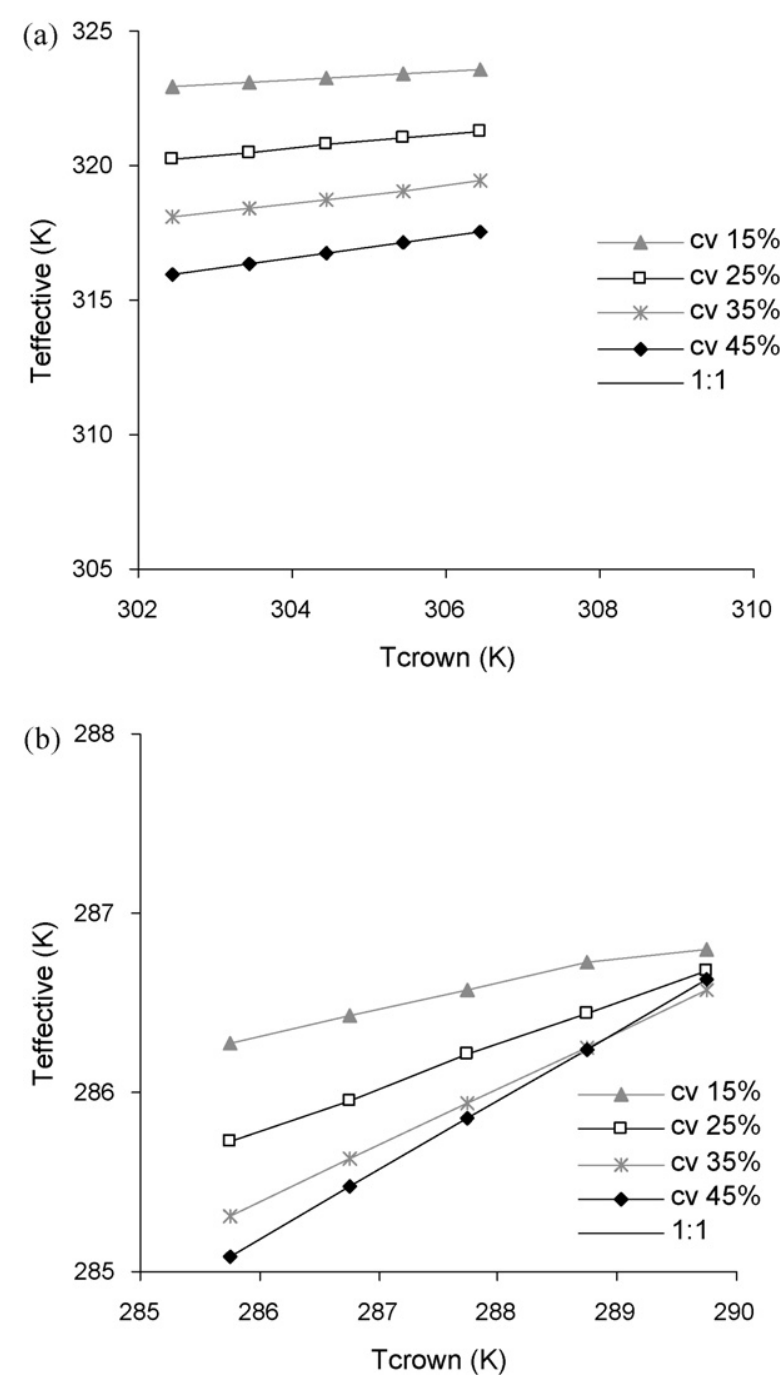

Fig. 14. Relationships between olive grove pixel temperature and canopy temperature for different vegetation percentage covers: (a) for summer and (b) for winter period.

The simulation to assess the aggregated temperature as function of crown temperature for different soil and tree densities in open canopies was conducted for different vegetation percentage cover levels (Fig. 14), considering both summer (Fig. 14a) and winter (Fig. 14b) cases. Results obtained for summer simulation yielded temperature differences between crown and effective pixel of $13 \mathrm{~K}$ for $45 \%$ vegetation percentage cover, increasing up to $20 \mathrm{~K}$ for $15 \%$ vegetation percentage cover due to the soil influence. These summer results demonstrate a canopy temperature overestimation caused when assuming aggregated-pixel temperature as vegetation temperature for open-tree canopies. Winter simulation results suggest smaller differences between crown and pixel temperature due to lower soil temperatures found. The large differences found between crown and aggregated pixel temperature for summer (ranging between 10 and $20 \mathrm{~K}$ depending on percentage cover) have important implications for ET estimations that rely on effective pixel instead of crop temperature as input for the energy balance equation in these open canopies.

\section{Conclusions}

Experimental results with 6-year ASTER imagery and 1076 ground-truth orchard information demonstrate that thermal 
ASTER imagery may detect temperature differences found as function of irrigation type (rainfed/irrigated) in open canopies. Thermal differences of up to $2 \mathrm{~K}$ between irrigated and rainfed fields with the same percentage cover were detected in summer, disappearing in winter ASTER imagery. A careful comparison of thermal differences for fields with similar percentage cover and vegetation density was conducted, using combined temperature, percentage cover and NDVI indicators. Field-to-field comparisons between irrigated and rainfed orchards under the same percentage cover showed that $\left(T-T_{\mathrm{a}}\right) / \mathrm{NDVI}$ index was capable of detecting consistent differences as function of the irrigation type.

A cumulative $\left(T-T_{\mathrm{a}}\right) / \mathrm{NDVI}$ index for the 6-year ASTER timeseries was the best indicator to discriminate between irrigated and rainfed orchards, yielding a 78\% agreement with the fact that irrigated orchards have lower $\left(T-T_{\mathrm{a}}\right) / \mathrm{NDVI}$ ratio than rainfed orchards for the same vegetation cover. Even when vegetation index comparisons were made under fixed NDVI intervals, $T$ seemed capable of detecting differences between irrigated and rainfed orchards, yielding $65 \%$ success. These results suggest that temperature contributes with additional information to NDVI for discriminating between irrigated and rainfed orchards.

Results obtained using a supervised classification method to visible, near infrared and temperature information for the 6 -year ASTER imagery yielded an overall accuracy of $75 \%$ and a kappa coefficient $(\kappa)$ of 0.34 , suggesting a reasonable identification of irrigated and rainfed olive orchards. These results suggest the capability of ASTER sensor to discriminate among irrigated and rainfed fields in open tree crops when percentage cover ranges between $15 \%$ and $55 \%$.

DART radiative transfer model in the thermal region was used to simulate different open canopy scenarios, accounting for pixel temperature as function of soil, percentage cover and LAI. A validation with high resolution AHS airborne imagery showed a good agreement between DART canopy simulation and AHS imagery when resampled to ASTER spatial resolution. Root mean square errors of $0.4,0.8$ and $0.6 \mathrm{~K}$ between DART-simulated scenes and airborne AHS imagery were obtained for 7:30, 9:30 and 12:30 GMT, respectively. Model simulations demonstrated consistency of ASTER thermal data as function of irrigation (irrigated and rainfed) and percentage cover. The sensitivity analysis conducted with DART enabled the assessment of inputs on the ASTER-aggregated pixel temperature differences. As expected, the influence of LAI on aggregated pixels for discriminating rainfed and irrigated orchards showed to be small $\left(T_{\text {rainfed }}-T_{\text {irrigated }}\right.$ ranging between 0.69 and 0.80 for $\mathrm{LAI}=1$ and $\mathrm{LAI}=5$, respectively, for leaf differences of $3 \mathrm{~K}$ ), but soil temperature highly influenced the differences between rainfed and irrigated orchards (yielding $4.7 \mathrm{~K}$ pixel temperature difference between rainfed and irrigated orchards with a soil temperature difference of $6 \mathrm{~K}$ for $55 \%$ percentage cover). These results demonstrate the importance of accounting for soil information data in open canopies. Under similar soil conditions, temperature differences between rainfed and irrigated orchards became almost negligible for percentages cover values lower than $15 \%$. Results suggest that the proposed methodology should be used for orchards with higher percentage cover values than $15 \%$ and for soil thermal differences (gradient irrigated - rainfed) below $1 \mathrm{~K}$. In canopies with $50 \%$ cover, soil thermal differences around $3 \mathrm{~K}$ between irrigated and rainfed soils would remove the detectable differences between rainfed and irrigated fields at pixel level.

The offset between pixel and crown temperature due to background effects was studied using DART model. Temperature differences obtained between pure crown and aggregated pixel yielded $13 \mathrm{~K}$ for $45 \%$ percentage cover, and $20 \mathrm{~K}$ for $15 \%$ percentage cover in summer. These large differences between crown and pixel temperature, mainly driven by soil effects, may be critical for accurate ET estimated in open canopies. This occurs when thermal remote sensing data from open canopies are inputs for single source evapotranspiration models based on the energy balance equation, conducting to erroneous sensible heat $(\mathrm{H})$ estimates. This manuscript demonstrates the need for radiative transfer models working in the thermal domain to account for scene components on aggregated pixels.

\section{Acknowledgments}

Financial support from Confederación Hidrográfica del Guadalquivir (CHG), and Empresa Pública para el Desarrollo Agrario y Pesquero (DAP) from Spain is gratefully acknowledged, as well as the support from Junta de Andalucía - Excelencia AGR-595, DIMAS (INCO-CT-2004-509087) and the Spanish Ministry of Science and Education (MEC) for the project AGL2005-04049 and CONSOLIDER CSD2006-67. Data access and technical support from Oleoestepa is acknowledged for technical support, as well as support provided by V. Vega and M. Pastor.

\section{References}

Allen, R.G., Tasumi, M., Morse, A., Trezza, R., 2005. A Landsat based energy balance and evapotranspiration model in western US water rights regulation and planning. Irrigation and Drainage Systems 19, 251-268.

Bastiaanssen, W.G.M., Menenti, M., Feddes, R.A., Holtslag, A.A.M., 1998. A remote sensing surface energy balance algorithm for land (SEBAL): 1. Formulation. Journal of Hydrology 212 (1-4), 198-212.

Berstein, L.S., Roberston, D.C., 1989. MODTRAN: a moderate resolution model for LOWTRAN 7. Geophys. Lab, Bedford, MA, Technical Report GL-TR-89-0122.

Chandler, C., Cheney, P., Thomas, P., Trabaud, L., Williams, D., 1983. Forest Fire Behaviour Effects. Fire in Forestry, I. Wiley, New York.

Chander, G., Markham, B., 2003. Revised Landsat-5 TM radiometric calibration procedures and postcalibration dynamic ranges. IEEE Transactions on Geoscience and Remote Sensing 41 (11), 2674-2677.

Fereres, E., Soriano, A., 2007. Deficit irrigation for reducing agricultural water use. Journal of Experimental Botany 58 (2), 147-159.

Gao, B.C., Goetz, A.F.H., 1995. Retrieval of equivalent water thickness and information related to biochemical components of vegetation canopies from AVIRIS data. Remote Sensing of Environment 52, 155-162.

Gastellu-Etchegorry, J.P., Bruniquel-Pinel, V., 2001. A modeling approach to assess robustness of spectrometric predictive equations for canopy chemistry. Remote Sensing of the Environment 76, 1-15.

Gastellu-Etchegorry, J.P., Demarez, V., Pinel, V., Zagolsky, F., 1996. Modeling radiative transfer in heterogeneous 3D vegetation canopies. Remote Sensing of Environment 58, 131-156

Gastellu-Etchegorry, J.P., Guillevic, P., Zagolski, F., Demarez, V., Trichon, V., Deering D., Leroy, M., 1999. Modeling BRF and radiation regime of tropical and boreal forests, Part I: BRF. Remote Sensing of Environment 68, 281-316.

Gillespie, A.R., Rokugawa, S., Hook, S., Matsunaga, T., Kahle, A.B., 1998. A temperature and emissivity separation algorithm for advanced spaceborne thermal emission and reflection radiometer (ASTER) images. IEEE Transactions on Geoscience and Remote Sensing 36, 1113-1126.

Guillevic, P., Gastellu-Etchegorry, J.P., Demarty, J., Prévot, L., 2003. Thermal infrared radiative transfer within three-dimensional vegetation covers. Journal of Geophysical Research 108 (D8), 4248, doi:10.1029/2002JD002247.

Goetz, S.J., 1997. Multisensor analysis of NDVI, surface temperature and biophysical variables at a mixed grassland site. International Journal of Remote Sensing 18 (1), 71-94.

Haboudane, D., Miller, J.R., Pattey, E., Zarco-Tejada, P.J., Strachan, I., 2004. Hyperspectral vegetation indices and novel algorithms for predicting green LAI of crop canopies: modeling and validation in the context of precision agriculture. Remote Sensing of Environment 90, 337-352.

Idso, S.B., Jackson, R.D., Pinter, P.J., Reginato, R.J., Hatfield, J.L., 1981. Normalizing the stress-degree-day parameter for environmental variability. Agricultural and Forest Meteorology 24, 45-55.

Ines, A., Honda, K., 2005. On quantifying agricultural and water management practices from low spatial resolution RS data using genetic algorithms: a numerical study for mixed-pixel environment. Advances in Water Resources 28 (8), 856-870.

Jackson, R.D., Idso, S.B., Reginato, R.J., Pinter Jr., P.J., 1981. Canopy temperature as a crop water stress indicator. Water Resources Research 17, 1133-1138.

Jackson, R.D., Reginato, R.J., Idso, S.B., 1977. Wheat canopy temperature: a practical tool for evaluating water requirements. Water Resources Research 13, 651-656.

Junta de Andalucía, 2005. Modelo Digital del Terreno de Andalucía. Relieve y Orografía. DVD. ISBN: 84-96329-34-8.

Kustas, W.P., Norman, J.M., 1996. Use of remote sensing for evapotranspiration monitoring over land surfaces. Hydrological Sciences-Journal des Sciences Hydrologiques 41, 495-516. 
G. Sepulcre-Cantó et al./Agricultural and Forest Meteorology 149 (2009) 962-975

975

Mo, X., Liu, S., Lin, Z., Xu, Y., Xiang, Y., McVicar, T.R., 2005. Prediction of crop yield, water consumption and water use efficiency with a SVAT-crop growth model using remotely sensed data on the North China Plain. Ecological Modelling 183, 301-322.

Nemani, R.R., Running, S.W., 1989. Estimation of regional surface resistance to evapotranspiration from NDVI and thermal IR AVHRR data. Journal of Applied Meteorology 28, 276-284

Moran, M.S., Clarke, T.R., Inoue, Y., Vidal, A., 1994. Estimating crop water deficit using the relation between surface-air temperature and spectral vegetation index. Remote Sensing of Environment 46, 246-263.

Peñuelas, J., Filella, I., Biel, C., Serrano, L., Save, R., 1993. The reflectance at the 950$970 \mathrm{~nm}$ region as an indicator of plant water status. International Journal of Remote Sensing 14, 1887-1905.

Pyne, S.J., Andrews, P.L., Laven, R.D., 1996. Introduction to Wildland Fire, 2nd ed. Wiley, New York.

Qi, J., Chehbouni, A., Huete, A.R., Kerr, Y., Sorooshian, S., 1994. A modified soil adjusted vegetation index (MSAVI). Remote Sensing of Environment 48, 119-126.

Richards, J.A., 1994. Remote Sensing Digital Image Analysis. An Introduction, 2nd ed. Springer-Verlag, Germany.

Rondeaux, G., Steven, M., Baret, F., 1996. Optimization of soil-adjusted vegetation indices. Remote Sensing of Environment 55, 59-107.

Rouse, J.W., Haas, R.H., Schell, J.A., Deering, D.W., Harlan, J.C., 1974. Monitoring the vernal advancements and retrogradation of natural vegetation in Nasa/Gsfc Final Report (ed. MD, U.G.) p. 371.

Sandholt, I., Rasmussen, K., Andersen, J., 2002. A simple interpretation of the surface temperature/vegetation index space for assessment of surface moisture status. Remote Sensing of Environment 79, 213-224.
Sepulcre-Cantó, G., Zarco-Tejada, P.J., Jiménez-Muñoz, J.C., Sobrino, J.A., de Miguel, E., Villalobos, F.J., 2006. Within-field thermal variability detection as function of water stress in Olea europaea L. orchards with high spatial remote sensing imagery. Agricultural and Forest Meteorology 136, 31-44.

Sepulcre-Cantó, G., Zarco-Tejada, P.J., Jiménez-Muñoz, J.C., Sobrino, J.A., Soriano, M.A., Fereres, E., Vega, V., Pastor, M., 2007. Monitoring yield and fruit quality parameters in open-canopy tree crops under water stress. Implications for ASTER. Remote Sensing of Environment 107, 455-470.

Sobrino, J.A., Jiménez-Muñoz, J.C., Zarco-Tejada, P., Sepulcre, G., de Miguel, E., 2006. Land surface temperature derived from airborne hyperspectral scanner thermal infrared data. Remote Sensing of Environment 102, 99-115.

Suárez, L., Zarco-Tejada, P.J., Sepulcre-Cantó, G., Pérez-Priego, O., Miller, J.R., Jiménez-Muñoz, J.C., Sobrino, J., 2007. Assessing canopy PRI for water stress detection with diurnal airborne imagery. Remote Sensing of Environment 112, 560575.

Tou, J.T., Gonzalez, R.C., 1974. Pattern Recognition Principles. Addison-Wesley Publishing Company, Reading, MA.

Ustin, S.L., Roberts, D.A., Pinzon, J., Jacquemoud, S., Gardner, M., Scheer, G., Castañeda, C.M., Palacios-Orueta, A., 1998. Estimating canopy water content of chaparral shrubs using optical methods. Remote Sensing of Environment 65, 280-291.

Zarco-Tejada, P.J., Miller, J.R., Morales, A., Berjón, A., Agüera, J., 2004. Hyperspectral indices and model simulation for chlorophyll estimation in open-canopy tree crops. Remote Sensing of Environment 90 (4), 463-476.

Zarco-Tejada, P.J., Whiting, M., Ustin, S.L., 2005. Temporal and spatial relationships between within-field yield variability in cotton and high-spatial hyperspectral remote sensing imagery. Agronomy Journal 97 (3), 641-653. 